\title{
Application of integrated BWM Fuzzy-MARCOS approach for coating material selection in tooling industries
}

\section{Sunil Kumar}

National Institute of Technology Silchar

Saikat Ranjan Maity ( $\nabla$ srmaity@mech.nits.ac.in )

National Institute of Technology Silchar

Lokeswar Patnaik

National Institute of Technology Silchar

\section{Research Article}

Keywords: Coating material selection, BWM, fuzzy-MARCOS, Optimization, Sensitivity analysis

Posted Date: September 22nd, 2021

DOI: https://doi.org/10.21203/rs.3.rs-925140/v1

License: (c) This work is licensed under a Creative Commons Attribution 4.0 International License.

Read Full License 


\title{
Application of integrated BWM Fuzzy-MARCOS approach for coating material selection in tooling industries
}

\author{
${ }^{\text {a }}$ Sunil Kumar, ${ }^{\text {a }}$ Saikat Ranjan Maity*, ${ }^{a}$ Lokeswar Patnaik \\ a Department of Mechanical Engineering, National Institute of Technology, Silchar, Assam - \\ 788010, India \\ *Corresponding author: saikat.jumtech@gmail.com
}

\begin{abstract}
The life of metal forming dies, and the efficiency of tooling industries depends on the mechanical and wear properties of tool steel. These properties can be further improved by depositing the ceramic coating on heat-treated tool steel. There are many coating materials available with numerous excellent properties. But problem is how to select the best coating material. Compared to various studies related to material selection problems in the contrasting area of utilization, remarkably, few research work is done in tooling industries. In the present work, we have identified eight coating materials (alternatives) and nine evaluation criteria under the consultation of an expert in the tooling application and tribological field. To deal with this coating material selection problem, an integrated fuzzy-MADM method is proposed comprising BWM and fuzzy-MARCOS. This integrated fuzzy-MADM method is used to evaluate the alternative, and the obtained results are scrutinized under extensive use of sensitivity analysis. In the first phase of analysis, seven scenarios of criteria weight change are used, which is derived by the BWM method; dynamic matrices are used in the second phase of analysis. In the third and fourth phases, obtained ranks are compared with those obtained by different weight calculation methods and ranking methods, respectively. All the phases have similar results, i.e., AlCrN/TiAlN coating (alternative $\mathrm{Cm}_{5}$ ) is the best coating material. What is more, the proposed method has been used to solve the published
\end{abstract}


results of coating material selection. To evaluate its reliability and robustness, a four phases comparative sensitivity analysis was performed.

Keywords: Coating material selection; BWM; fuzzy-MARCOS; Optimization; Sensitivity analysis

Abbreviations
\begin{tabular}{|l|l|}
\hline MADM & Multi attributed decision making \\
\hline BWM & Best Worst method \\
\hline AHP & Analytic Hierarchy Process \\
\hline STDEV & Standard deviation \\
\hline CRITIC & Criteria Importance Through Intercriteria Correlation \\
\hline MEREC & Method Based on the Removal Effects of Criteria \\
\hline F-MARCOS & Fuzzy Measurement Alternatives and Ranking according to the Compromise \\
\hline F-TOPSIS & Solution \\
\hline F-COPRAS & Fuzzy Complex Proportional Assessment \\
\hline F-WASPAS & Fuzzy Weighted Aggregates Sum Product Assessment \\
\hline F-MABAC & Fuzzy multi-attributive border approximation area comparison \\
\hline F-CODAS & Fuzzy Combinative Distance-based Assessment \\
\hline F-EDAS & Fuzzy Evaluation Based on Distance from Average Solution \\
\hline
\end{tabular}

\section{Introduction}

Material selection for the design and development of any die element in the tooling industries plays an important role because each die element is essential during its application. That's why tool steel has been categorized mainly into cold work and hot work tool steel. Several tool steels were developed in the past decade under the following standard: AISI, DIN, BS, JIS, AS, etc. For example, D2, O1, and A1 are cold work tool steel, and H11, H13, and H21 are hot work tool steel under AISI standards. These tool steels are heat-treated to obtain the required properties for the particular application (Kheirandish et al. 2010; Lesyk et al. 2017; Huber et al. 2019; Deirmina et al. 2019; Gonzalez-Pociño et al. 2019; Kumar et al., 2021a); sometimes, the heat-treated tool steels nitrided to improve the surface properties (Díaz-Guillén et al. 2020; Miyamoto et al. 2019; 
Fathallah et al. 2019; Díaz-Guillén et al. 2018; Abreu et al. 2020; Podgornik et al. 2012). The production can be run without any interruption. Literature (Kumar et al. 2021a; Kumar et al. 2020; Staia et al. 2009) suggested that the obtained property of tool steel is not sufficient for the rapid and long run of production because heat-treated die elements do not have enough hardness and surface properties to withstand unavoidable wear during rapid production. It leads to frequent maintenance (resharpening, replacement of die elements, etc.) after few thousand of part production. Because of that tooling industries faces unintentional restriction in the production process, machine ideal time and maintenance time and finally, it pushes towards loss. Many researchers suggested the application of ceramic coating over heat-treated tool steels (Kumar et al. 2021b; Kumar et al. 2020b; Sousa et al. 2021; Patel et al. 2020).

In this era of research on ceramic coating, the tool design engineer has countless options to choose a coating material. Each coating material possesses excellent properties over others, and it creates a selection problem in front of the tool design engineer. Thus, the coating material selection process needs sound knowledge about the coating material related to a particular application or an experiment. Experimentation is a big challenge in itself because it is a time and cost consuming process. The final selection is to pass on the result interpretation, which leads to a conflict between the tool design engineers. This study focuses on the crucial issues during the coating material selection:

- What factors and their weightage should be considered when selecting the best coating material and the evaluations of experts who are highly experienced in the coating application?

- What can a suitable integrated MADM method be used to derive the criteria weight and ranking of alternatives?

- Are obtained results reliable, which derived by the integrated MADM method?

This study has provided the systematic framework, which includes the BWM (best-worst method) method (Rezaei 2015) integrated to fuzzy-MARCOS (measurement of alternatives and ranking according to compromise solution) method (Stević et al. 2020) to select the best coating material for tooling industries. Evaluation and the rating of the coating alternatives and their criteria weight was done in the linguistic term given by the expert's committee. Approach towards real and practical scenarios, the alternatives were evaluated against the quantitative criteria. To 
deal effectively with these linguistic terms, it observed that fuzzy numbers are the best suitable number as the researchers wildly used it. Thus, we have to expand the MADM method to the fuzzy-MADM method. Here, coating material selection was considered as the case study. There is the total of eight coating materials (alternatives) have been recognized. These coating alternatives are analyzed based on nine coating properties (criteria) which are selected in the presence of experts involved in coating application. We have used the above-mentioned fuzzy-MADM method to analyze and rank the alternatives. Finally, the obtained results were validated and tested by using the sensitivity analysis with four steps procedures. These procedures are (i) effect of criteria weight change on the ranking, (ii) effect of criteria weight derived from other methods, (iii) effect of dynamic matrices on the ranking, and (iv) comparison with other well established MADM methods. In addition to this, the proposed method is tested by solving the different published results for coating material selection.

The rest of the paper is organized in such a way that related work and research gaps are described in section 2. A detailed description of the proposed methodology can be found in section 3. Coating material selection is discussed in section 4. Validation and testing of the proposed methodology have been elaborated in section 5 . The zest of the work combined with results and interpretation with a future scope is finally concluded in section 6 .

\section{Related work}

This section presents the overview of work done on the selection of coating materials for tooling industries. In the case of tooling industries, analyzing and selecting coating material is a serious issue. It is directly related to the failure of the die elements that interrupt the continuous production. In this regard, countless studies are available on the selection of materials in various areas of application (Maity and Chakraborty 2015; Mousavi-Nasab et al. 2017; Niu et al. 2020), but comparatively less work has been done on coating material selection (Podgornik et al. 2006; Saber-Samandari et al. 2011). Athanasopoulos et al. (2009) were proposed a fuzzy TOPSIS approach to select a suitable coating material. In this approach, Max-Min Set was used to determine the ordering value of the alternative, while TOPSIS was used to rank it. Sustainable coating material was selected to enhance the boiling heat transfer using multi-MADM methods, where the weight of criteria was calculated using entropy and AHP methods (Mogra et al. 2021). Suitable coating material for AISI4140 steel was selected using the TOPSIS method to improve 
the tribological properties of the steel, and the criteria weight was calculated using the entropy method (Pahan et al. 2018). 316 SS coating material was selected as the best suitable material using the AHP-TOPSIS method to improve the corrosion resistance of magnesium alloy (Prasad et al. 2020). Robinson et al. (1993) were employed a PRECEPT knowledge-based computer system to select a suitable coating material to reduce the wear of surfaces and improve the corrosion resistance. Firojkhan et al. (2020) proposed a novel AHP integrated TOPSIS approach to select a sustainable coating material for bearing application. They found that nitrided and WCC coated steel was the best suitable material for the mentioned application. Chauhan et al. (2013) used the TOPSIS method to rank the coating materials with the Ashby approach (Material selection chart). They concluded that TOPSIS and Ashby's approach has good agreement with each other. Petković et al. (2015) proposed the COPRAS and WASPAS method, and the results were later compared with the TOPSIS method.

In addition to this, some researchers have used comparative experimental studies on coating material selection for tooling industries (Sousa et al. 2021; Adesina et al. 2018; Das et al. 2017). Kara et al. (2019) were deposited different thin films on AISI H13 tool steel. The frictional and wear behavior of coating was investigated against the $\mathrm{Al}_{2} \mathrm{O}_{3}$ counter body. Souza et al. (2020) were deposited a thin film of $\mathrm{AlCrN}$ and TiAlN on AISI M2 tool steel. They found, AlCrN has good nanomechanical and wears resistance properties compared to TiAlN coating. Beake et al. (2017) have conducted the micro-scratch test on TiAlN, AlCrN, and AlTiN coatings under different atmospheres $\left(25^{\circ} \mathrm{C}\right.$ and $\left.500^{\circ} \mathrm{C}\right)$. They observed that TiAlN coating has a lower critical load at $25^{\circ} \mathrm{C}$ than $\mathrm{AlCrN}$ and AlTiN coating, whereas AlTiN shows excellent wear resistance than the AlCrN and TiAlN coatings. Dumkum et al. (2019) were deposited different coating on tungsten carbide, and they observed AlCrN/TiAlN coating possess high hardness and TiAlN coating have low surface roughness while AlCrN/TiN coating has a low lower critical load $\left(\mathrm{L}_{\mathrm{c} 1}\right)$ among all the coatings. AlCrN coating showed excellent wear resistance, while $\mathrm{CrN}$ coating reveals a low coefficient of friction (Jokar et al. 2019). Mechanical and tribological results show AlCrN coating possesses high hardness and excellent wear resistance than the TiAlN and AlTiN coatings against boundary lubrication (Özkan et al. 2018). Chandrashekhar et al. (2016) were deposited AlCrN and TiAlN coating on EN-353 steel, and they observed AlCrN coating has excellent mechanical and wear properties compare to TiAlN coating. 
The introductory literature on coating material selection proved that selection of the coating material is very tedious work. In the past study, researchers have selected coating material based on a pilot experiment, which is also time-consuming and quite expensive. The experimental result interpretation and its comparison play a significant role in the selection of sustainable coating material. This process is only feasible for small numbers of coating materials. If the number of coating materials increases, it becomes more tedious and irritating to select the suitable coating material, and sometimes it leads to wrong coating material selection. This inappropriate coating material increases the failure frequency of die elements, resulting in high maintenance time and machine ideal time. Thus, the present work proposes a fuzzy integrated MADM approach and its application to select the sustainable coating material for tooling industries. In the past study (Chauhan et al. 2013; Petković et al. (2015)), only bilayer coatings and mechanical properties were considered alternative and selection criteria. However, numerous coating materials (monolayer, bilayer, and multilayer) are available for tooling applications. The wear properties of coating material play a significant role in tooling application, which was not considered in the past study (Chauhan et al. 2013; Petković et al. 2015). Hence, in this study, wear and mechanical properties of coating material were considered as evaluation criteria.

\section{The proposed integrated BWM fuzzy-MADM Methodology}

The proposed MADM method consisting of four easy stages of algorithm as presented in Fig. 1. At the initial stage, a group of decision-maker formed by the researcher and the alternatives and their criteria weight was determined together.

In the next stage, the BWM method is implemented to calculate the criteria weight. At the same time, the fuzzy-MARCOS method is implemented to evaluate and rating the coating alternatives. Based on this evaluation, the alternative is ranked. Both the methods are discussed briefly in sections 3.2.1 and 3.2.2, respectively. In the final stage, the obtained result is validated and tested using comprehensive sensitivity analysis and solving the other published results using the fuzzy-MARCOS method. 


\subsection{Fuzzy membership function}

In this study, a particular type of triangular fuzzy number (TFN) was used (Kundu et al. 2021), and it is presented as $\tilde{N}=(l, m, u)$ on $\sim$. The membership function of it $\mu_{\tilde{N}}(x): \sim \rightarrow[0,1]$ is allocated by:

$$
\mu_{\tilde{N}}(x)= \begin{cases}\frac{x-l}{m-l} & l \leq x \leq m \\ \frac{u-x}{u-m} & m \leq x \leq u \\ 0 & \text { otherwise }\end{cases}
$$

In the above expression, lower and upper bound of fuzzy number $(\tilde{N})$ is represented by $l$ and $u$ respectively, while model value represented by $\mathrm{m}$. The TFN is commonly used fuzzy number which denote existence of imprecision in the expression. TFN and fuzzy sets formulation are briefly presented in the following section. Many researchers have used TFN in MADM method (Salih et al. 2019; Ecer et al. 2020; Fallahpour et al. 2021).

Following are the arithmetic operation for two triangular fuzzy numbers $\tilde{A}=\left(a^{l}, a^{m}, a^{u}\right)$ and $\tilde{B}=\left(\mathrm{b}^{l}, \mathrm{~b}^{m}, \mathrm{~b}^{u}\right)($ Ulutas et al. 2019):

Addition: $\tilde{A}+\tilde{B}=\left(a^{l}+\mathrm{b}^{l}, a^{m}+\mathrm{b}^{m}, a^{u}+\mathrm{b}^{u}\right)$

Subtraction: $\tilde{A}-\tilde{B}=\left(a^{l}-\mathrm{b}^{l}, a^{m}-\mathrm{b}^{m}, a^{u}-\mathrm{b}^{u}\right)$

Multiplication: $\tilde{A} \times \tilde{B}=\left(\min \left(a^{l} \mathrm{~b}^{l}, a^{l} \mathrm{~b}^{u}, a^{u} \mathrm{~b}^{l}, a^{u} \mathrm{~b}^{u}\right), \max \left(a^{l} \mathrm{~b}^{l}, a^{l} \mathrm{~b}^{u}, a^{u} \mathrm{~b}^{l}, a^{u} \mathrm{~b}^{u}\right)\right)$

Division: $\tilde{A} \div \tilde{B}=\left(\min \left(\frac{a^{l}}{\mathrm{~b}^{l}}, \frac{a^{l}}{\mathrm{~b}^{u}}, \frac{a^{u}}{\mathrm{~b}^{l}}, \frac{a^{u}}{\mathrm{~b}^{u}}\right), \frac{a^{m}}{\mathrm{~b}^{m}}, \max \left(\frac{a^{l}}{\mathrm{~b}^{l}}, \frac{a^{l}}{\mathrm{~b}^{u}}, \frac{a^{u}}{\mathrm{~b}^{l}}, \frac{a^{u}}{\mathrm{~b}^{u}}\right)\right)$

Scalar division: for positive real number $\mathrm{c} ; \tilde{A} / c=\left(\frac{a^{l}}{c}, \frac{a^{m}}{c}, \frac{a^{c}}{c}\right)$ 


\subsection{Integrated fuzzy MADM method comprising BWM and fuzzy-MARCOS approach}

In this stage of the proposed methodology, the BWM method was implemented to deriving the criteria weights. The method has a fundamental algorithm comprising six steps to implement. After deriving the criteria weight, fuzzy-MARCOS was implemented to determine the ranking of alternatives.

\subsubsection{BWM method}

The BWM method is the novel weight choosing method to obtain the criteria weight and was developed by Professor Rezaei (Rezaei 2015). In this method, the decision-maker chooses the best and worst criteria representing a reference point for comparing the criteria. The reference comparison was performed concerning the best and the worst criteria. This comparison was performed between the best and other criteria; similarly, it was performed for the worst. This method also uses the idea of comparison between two criteria similar to the AHP method (Maghsoodi et al. 2019). The BWM method requires a smaller comparison and is more consistent than the ANP, SMART, FARE, and AHP methods (Yadav et al. 2018a \& 2018b). Finally, this method is well known for its simplicity because it compares criteria using an integer number between 1 to 9 . The main advantage is compared to other methods that use comparison matrices with fractional and integer numbers. Hence, the present study decided to use this method to determine the weight of criteria and use it as additional proof for the applicability. The basic algorithm of the BWM method is completed in the following six steps (Rezaei 2015).

Step-1 Establishment of criteria set as $\left\{c_{1}, c_{2}, c_{3}, \ldots \ldots . . c_{n}\right\}$.

Step-2 Obtain the best and worst criterion based on the assessment of the decision-maker.

Step-3 Obtain the most important criteria over all other criteria using integer numbers 1 to 9 . The obtained BO (best to other) vector would be:

$$
A_{B}=\left(a_{B 1}, a_{B 2}, a_{B 3}, \ldots \ldots, a_{B n}\right)
$$

where the preference of the most important criteria (B) is denoted as $a_{B j}$ over the criterion $j$ and $a_{B B}=1$. 
Step-4 Obtain the preference of all the criteria over the least important criteria using integer numbers 1 to 9 . The obtained OW (other to worst) vector would be:

$$
A_{W}=\left(a_{1 W}, a_{2 W}, a_{3 W}, \ldots \ldots ., a_{n W}\right)^{T}
$$

where the preference of criterion $j$ is denoted by $a_{j w}$ over the least important criterion $W$ and $a_{w w}=$ 1.

Step-5 Calculate the optimal weight $\left(w_{1}^{*}, w_{2}^{*}, w_{3}^{*}, \ldots \ldots \ldots . ., w_{n}^{*}\right)$

The aim is to calculate the optimal weights for the criteria to minimize the maximum absolute differences for the $\left|w_{B} / w_{i}-a_{B i}\right|$ and $\left|w_{i} / w_{W}-a_{i W}\right|$ for all $j$. Based on the assumption (total sum of the weight equal to 1 and no negativity constraints), Rezaei (Rezaei 2015) developed the linear BWM as follows:

$$
\min \xi
$$

s. t:

$\left|w_{i}-a_{i w} w_{W}\right| \leq \xi, \quad \mathrm{i}=1,2,3, \ldots \ldots, \mathrm{n}$

$\left|w_{B}-a_{B i} w_{i}\right| \leq \xi, \quad \mathrm{i}=1,2,3, \ldots \ldots, \mathrm{n}$

$\sum_{i=1}^{n} w_{i}=1$

$w_{i} \geq 0, \quad \mathrm{j}=1,2,3, \ldots \ldots \ldots, \mathrm{n}$

Step-6 Finally, the consistency ratio needs to calculate using Eq. (10), which checks the consistency of pairwise comparison. If the calculated value follows this equation means pairwise comparison possesses full consistency; otherwise, inconsistency occurs. The value of the consistency index $(C I)$ is presented in (Rezaei 2015).

$$
C R=\frac{\xi}{C I}
$$




\subsubsection{Preference evaluation of coating alternatives using fuzzy-MARCOS approach}

In order to perform the determination of significance values of the alternatives, the fuzzyMARCOS method integrated with the BWM method has been executed. This method works based on a defined relationship between alternatives and their reference point (ideal and non-ideal alternatives). Further, the utility function needs to be calculated for each alternative using this defined alternative. In relation to ideal and non-ideal solutions, the compromised ranking was obtained. The value of the utility function denotes the actual location of the alternative concerning the ideal and non-ideal solutions. The best suitable alternative is nearer to the ideal solution and far from the non-ideal solution. The basic algorithm of this methodology comprising manly ten steps (Kundu et al. 2021):

Here $\mathrm{Cm}_{1}, \mathrm{Cm}_{2}, \ldots \ldots, \mathrm{Cm}_{\mathrm{n}}$ represent the alternatives while the criteria are represented by $\mathrm{C}_{1}, \mathrm{C}_{2}$, ........, $\mathrm{C}_{\mathrm{n}}$.

Step-1: Construct the aggregated decision matrix in a fuzzy environment. The panel of decisionmakers constructed this matrix, and it is represented as

$\tilde{D}=\left[\tilde{\mathrm{r}}_{i j}\right]_{\mathrm{m} \times \mathrm{n}}$

Here $\tilde{r}_{i j}$ is the aggregated rating value of $i^{t h}$ alternative with respect to $j^{\text {th }}$ criterion, and it is obtained using Eq. (12)

$\tilde{\mathrm{r}}_{i j}=\prod_{k=1}^{K}\left(\tilde{\mathrm{r}}_{i j k}\right)^{1 / K}, i=1,2,3 \ldots \ldots . ., m ; j=1,2,3 \ldots . . n$

In the above expression, fuzzy preference rating is denoted by $\tilde{\mathrm{r}}_{i j k}$, and it is also an element of a matrix presented in Eq. (11). It is determined for $i^{\text {th }}$ alternative with respect to criterion $j^{\text {th }}$ by $k^{\text {th }}$ expert. This matrix is constructed using a geometric mean.

Step-2: Constructing the fuzzy decision matrix by expanding the initial matrix (Eq. 13). In this step, the best ( $A I$ - Ideal solution) and worst ( $A A I$ - Anti Ideal solution) preference values of the options with respect to criterion are derived. The values are integrated into the expanded fuzzy decision matrix. Maximum value will consider beneficial criteria as the best preference, while minimum value will consider cost criteria as the worst preference. The lowest value will be the 
ideal solution, and the highest value will be the anti-ideal solution in the case of cost criteria. The expanded fuzzy decision matrix is constructed as follows:

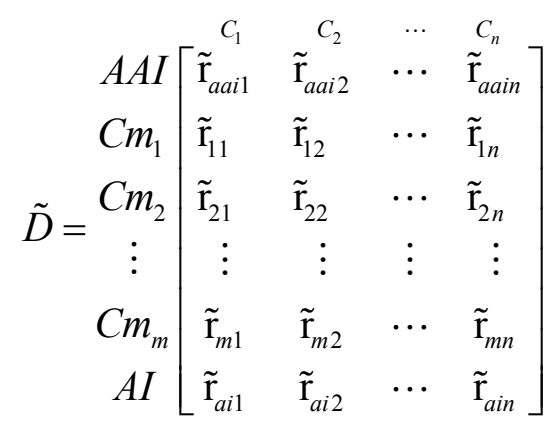

Step-3: In this step, fuzzy normalized matrix is constructed using Eq. (14) and Eq. (15) for beneficial and cost criteria respectively.

$$
\begin{aligned}
& \tilde{n}_{i j}=\left(n_{i j}^{l}, n_{i j}^{m}, n_{i j}^{u}\right)=\left(\frac{r_{i j}^{l}}{r_{a i}^{u}}, \frac{r_{i j}^{m}}{r_{a i}^{u}}, \frac{r_{i j}^{u}}{r_{a i}^{u}}\right) \\
& \tilde{n}_{i j}=\left(n_{i j}^{l}, n_{i j}^{m}, n_{i j}^{u}\right)=\left(\frac{r_{a i}^{l}}{r_{i j}^{u}}, \frac{r_{a i}^{l}}{r_{i j}^{m}}, \frac{r_{a i}^{l}}{r_{i j}^{l}}\right)
\end{aligned}
$$

Step-4: Generate the weighted fuzzy normalized decision matrix by multiplying the criteria weight to the fuzzy normalized decision matrix.

$$
\tilde{v}_{i j}=\left(v_{i j}^{l}, v_{i j}^{m}, v_{i j}^{u}\right)=\tilde{n}_{i j} \otimes w_{j}=\left(n_{i j}^{l} \times w_{j}, n_{i j}^{m} \times w_{j}, n_{i j}^{u} \times w_{j}\right)
$$

Step-5: Determine the total weight value for each alternative using following Eq. (17):

$$
\tilde{S}_{i}=\sum_{j=1}^{n} \tilde{v}_{i j}
$$

Here, $\tilde{S}_{i}$ it represents the sum of a weighted normalized matrix with respect to $i^{\text {th }}$ alternative. Similarly, determine the total weighted value for $\operatorname{ideal}\left(\tilde{S}_{a i}\right)$ and non-ideal $\left(\tilde{S}_{a a i}\right)$ solutions, respectively.

Step-6: Calculate the utility degree of each alternative using Eq. (18) and Eq. (19). 


$$
\begin{aligned}
& \tilde{K}_{i}^{-}=\frac{\tilde{S}_{i}}{\tilde{S}_{a a i}}=\left(\frac{s_{i}^{l}}{s_{a a i}^{u}}, \frac{s_{i}^{m}}{s_{a a i}^{m}}, \frac{s_{i}^{u}}{s_{a a i}^{l}}\right) \\
& \tilde{K}_{i}^{+}=\frac{\tilde{S}_{i}}{\tilde{S}_{a i}}=\left(\frac{s_{i}^{l}}{s_{a i}^{u}}, \frac{s_{i}^{m}}{s_{a i}^{m}}, \frac{s_{i}^{u}}{s_{a i}^{l}}\right)
\end{aligned}
$$

Ste-7: Obtain the total utility degree of each alternative using Eq. (20).

$$
\tilde{t}_{i}=\left(t_{i}^{l}, t_{i}^{m}, t_{i}^{u}\right)=\tilde{K}_{i}^{-} \oplus \tilde{K}_{i}^{+}=\left(k_{i}^{-l}+k_{i}^{+l}, k_{i}^{-m}+k_{i}^{+m}, k_{i}^{-u}+k_{i}^{+u}\right)
$$

Further, new fuzzy number $(\tilde{d})$ is calculated using Eq. (21).

$$
\tilde{d}=\left(d^{l}, d^{m}, d^{u}\right)
$$

Here, $d^{l}=\max _{i} t_{i}^{l}, d^{m}=\max _{i} t_{i}^{m}, d^{u}=\max _{i} t_{i}^{u}$

Now, perform defuzzification to obtain defuzzified number using Eq. (22).

$d f_{c r i s p}=\frac{d^{l}+\left(4 \times d^{m}\right)+d^{u}}{6}$

Step-8: In this step, utility function is described for ideal and anti-ideal solution using Eq. (23) and Eq. (24) respectively.

$$
\begin{aligned}
& f\left(\tilde{K}_{i}^{+}\right)=\frac{\tilde{K}_{i}^{-}}{d f_{\text {crisp }}}=\left(\frac{k_{i}^{-l}}{d f_{\text {crisp }}}, \frac{k_{i}^{-m}}{d f_{\text {crisp }}}, \frac{k_{i}^{-u}}{d f_{\text {crisp }}}\right) \\
& f\left(\tilde{K}_{i}^{-}\right)=\frac{\tilde{K}_{i}^{+}}{d f_{\text {crisp }}}=\left(\frac{k_{i}^{+l}}{d f_{\text {crisp }}}, \frac{k_{i}^{+m}}{d f_{\text {crisp }}}, \frac{k_{i}^{+u}}{d f_{\text {crisp }}}\right)
\end{aligned}
$$

Step-9: Using Eq. (25), calculate the utility function for each alternative.

$$
f\left(K_{i}\right)=\frac{K_{i}^{+}+K_{i}^{-}}{1+\frac{1-f\left(K_{i}^{+}\right)}{f\left(K_{i}^{+}\right)}+\frac{1-f\left(K_{i}^{-}\right)}{f\left(K_{i}^{-}\right)}}
$$

Here, $K_{i}^{-}, K_{i}^{+}, f\left(K_{i}^{-}\right)$and $f\left(K_{i}^{+}\right)$denotes the proportional defuzzified values. 
Step-10: Based on the obtained utility function, determine the ranking of alternatives. The highest value of the utility function is derived as the best alternative.

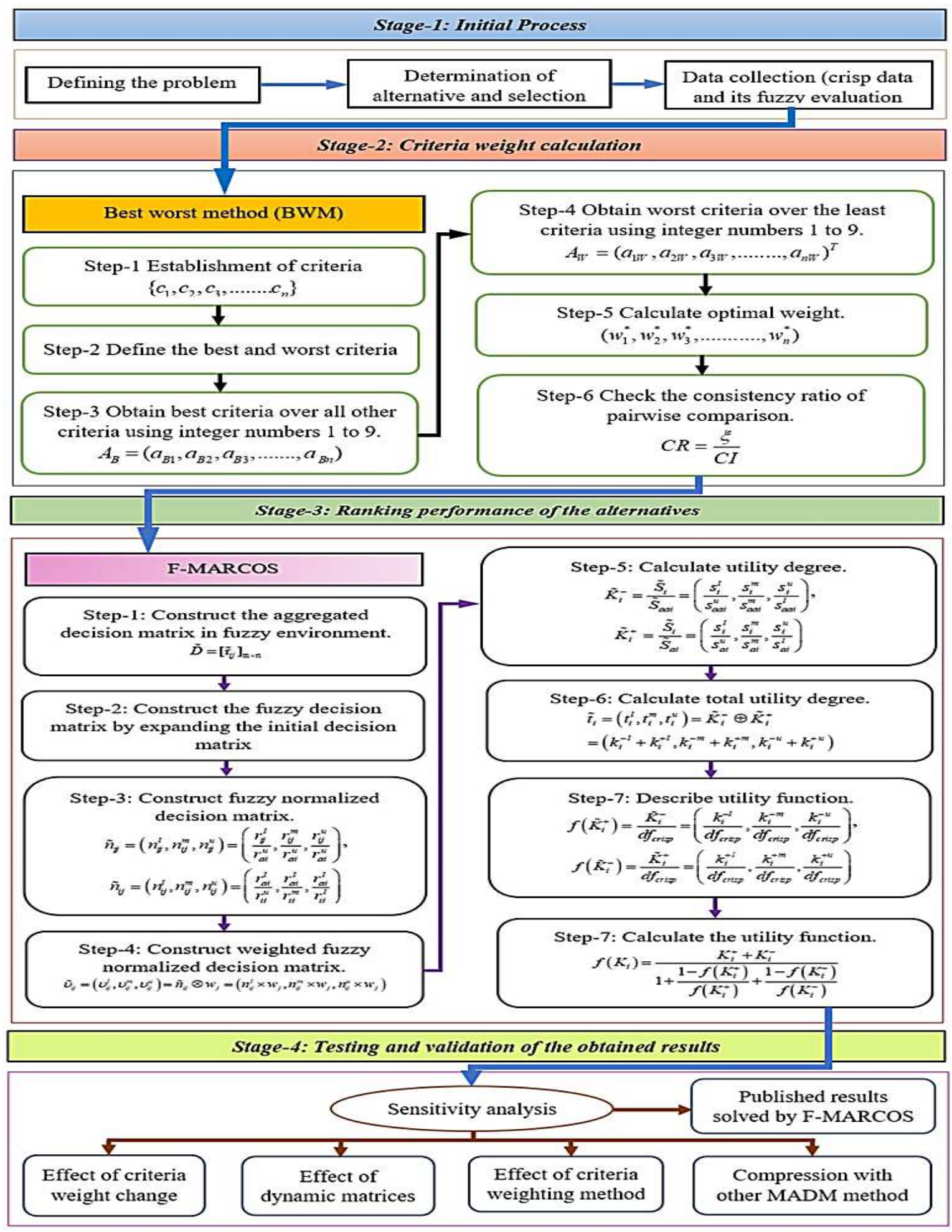

Fig. 1 Algorithm of the proposed integrated BWM fuzzy MARCOS approach 


\section{Coating material selection using integrated BWM fuzzy-MARCOS approach}

In this part of the study, we have considered the coating material selection problem for tooling industries. As already discussed, the selection of suitable coating for tooling application cannot be solely dependent upon its mechanical properties. Several other criteria must be considered in selecting coating material. To solve this MADM problem, we have implemented the integrated MADM methodology as discussed previously (section 3). In this study, there are nine criteria (Table 2) selected based on those eight alternatives (Table 1) were evaluated. Then, the initial fuzzy decision matrix consisting of eight coating material alternatives and nine significant criteria is presented in Table 3. The criteria values were taken from literature for the coating TiAlN, AlCrN, Cr-(CrN/TiN), TiN, Cr-(CrN/TiAlN), and TiCrN (Kumar et al. 2020a; 2021b; 2020b; 2021c \& 2021d) and values for remaining coatings were obtained from experiment. In the second step, the model is generated for determining the criteria weight.

Table 1 Coating material alternatives

\begin{tabular}{|l|c|}
\hline Coating materials alternative & Symbol \\
\hline TiN & $\mathrm{Cm}_{1}$ \\
\hline TiCrN & $\mathrm{Cm}_{2}$ \\
\hline TiAlN & $\mathrm{Cm}_{3}$ \\
\hline $\mathrm{AlCrN}$ & $\mathrm{Cm}_{4}$ \\
\hline $\mathrm{AlCrN} / \mathrm{TiAlN}$ & $\mathrm{Cm}_{5}$ \\
\hline $\mathrm{Cr}-(\mathrm{CrN} / \mathrm{TiN})$ & $\mathrm{Cm}_{6}$ \\
\hline $\mathrm{Cr}-(\mathrm{CrN} / \mathrm{TiAlN})$ & $\mathrm{Cm}_{7}$ \\
\hline $\mathrm{Cr}_{2} \mathrm{O}_{3} / \mathrm{TiAlN}$ & $\mathrm{Cm}_{8}$ \\
\hline
\end{tabular}

Table 2 Selection criteria of coating material

\begin{tabular}{|l|c|}
\hline Properties of coating materials (criteria) & Symbol \\
\hline Hardness $(\mathrm{H}$, in $\mathrm{Gpa})$ & $\mathrm{C}_{1}$ \\
\hline Young's modulus $(\mathrm{E}$, in $\mathrm{GPa})$ & $\mathrm{C}_{2}$ \\
\hline Wear resistance $(\mathrm{H} / \mathrm{E})$ & $\mathrm{C}_{3}$ \\
\hline Plastic Deformation $\left(\mathrm{H}^{3} / \mathrm{E}^{2}\right.$, in $\left.\mathrm{GPa}\right)$ & $\mathrm{C}_{4}$ \\
\hline Strain hardening exponent $(\mathrm{n})$ & $\mathrm{C}_{5}$ \\
\hline
\end{tabular}




\begin{tabular}{|l|c|}
\hline Coefficient of thermal expansion $\left(\mathrm{K}^{-1}, \times 10^{-6}\right)$ & $\mathrm{C}_{6}$ \\
\hline Surface roughness $(\mathrm{Ra}$, in $\mu \mathrm{m})$ & $\mathrm{C}_{7}$ \\
\hline Coefficient of friction $(\mathrm{CoF})$ & $\mathrm{C}_{8}$ \\
\hline Wear rate $\left(\mathrm{K}\right.$, in $\left.\mathrm{mm}^{3} / \mathrm{Nm}\right)$ & $\mathrm{C}_{9}$ \\
\hline
\end{tabular}

Table 3 Initial fuzzy diction matrix for evaluating the coating material alternatives

\begin{tabular}{|c|c|c|c|c|c|}
\hline Alternative & $\mathrm{C}_{1}$ & $\mathrm{C}_{2}$ & $\mathrm{C}_{3}$ & $\mathrm{C}_{4}$ & $\mathrm{C}_{5}$ \\
\hline $\mathrm{Cm}_{1}$ & $(18,21,24)$ & $(362,372,382)$ & $(0.050,0.057,0.063)$ & $(0.045,0.067,0.095)$ & $(0.31,0.32,0.33)$ \\
\hline $\mathrm{Cm}_{2}$ & $(17,20,23)$ & $(318,330,342)$ & $(0.053,0.061,0.067)$ & $(0.049,0.074,0.104)$ & $(0.29,0.3,0.31)$ \\
\hline $\mathrm{Cm}_{3}$ & $(31,35,39)$ & $(350,359,368)$ & $(0.089,0.098,0.106)$ & $(0.243,0.333,0.438)$ & $(0.39,0.4,0.41)$ \\
\hline $\mathrm{Cm}_{4}$ & $(27,32,37)$ & $(361,368,375)$ & $(0.075,0.087,0.099)$ & $(0.151,0.242,0.360)$ & $(0.33,0.35,0.37)$ \\
\hline $\mathrm{Cm}_{5}$ & $(35,38,41)$ & $(409,423,437)$ & $(0.086,0.090,0.094)$ & $(0.256,0.313,0.361)$ & $(0.43,0.44,0.45)$ \\
\hline $\mathrm{Cm}_{6}$ & $(26,28,30)$ & $(339,347,355)$ & $(0.077,0.081,0.085)$ & $(0.153,0.182,0.214)$ & $(0.32,0.34,0.36)$ \\
\hline $\mathrm{Cm}_{7}$ & $(37,40,43)$ & $(358,367,376)$ & $(0.103,0.109,0.114)$ & $(0.395,0.475,0.562)$ & $(0.41,0.42,0.43)$ \\
\hline $\mathrm{Cm} 8$ & $(33,38,43)$ & $(374,387,400)$ & $(0.088,0.098,0.108)$ & $(0.257,0.366,0.497)$ & $(0.35,0.36,0.37)$ \\
\hline Alternative & \multicolumn{2}{|c|}{$\mathrm{C}_{6}$} & $\mathrm{C}_{7}$ & $\mathrm{C}_{8}$ & $\mathrm{C}_{9}$ \\
\hline $\mathrm{Cm}_{1}$ & \multicolumn{2}{|c|}{$(8.14,9.35,10.56)$} & $(0.24,0.26,0.28)$ & $(0.3,0.32,0.34)$ & $(11.72,12.46,13.2)$ \\
\hline $\mathrm{Cm}_{2}$ & \multicolumn{2}{|c|}{$(3.03,3.21,3.39)$} & $(0.28,0.31,0.34)$ & $(0.42,0.43,0.44)$ & $(9.24,9.73,10.22)$ \\
\hline $\mathrm{Cm}_{3}$ & \multicolumn{2}{|c|}{$(6.6,7.5,8.4)$} & $(0.28,0.32,0.36)$ & $(0.52,0.55,0.58)$ & $(6.11,6.62,7.13)$ \\
\hline $\mathrm{Cm}_{4}$ & $(5.2,5$ & $6.6)$ & $(0.37,0.39,0.41)$ & $(0.55,0.57,0.59)$ & $(7.24,7.87,8.5)$ \\
\hline $\mathrm{Cm}_{5}$ & $(6.6,7)$ & $8.4)$ & $(0.21,0.24,0.27)$ & $(0.48,0.49,0.5)$ & $(6.2,6.61,7.02)$ \\
\hline $\mathrm{Cm}_{6}$ & $(8.14,9$. & 10.56) & $(0.22,0.27,0.32)$ & $(0.3,0.33,0.36)$ & $(8.41,8.94,9.47)$ \\
\hline $\mathrm{Cm}_{7}$ & $(6.6,7)$ & $8.4)$ & $(0.39,0.42,0.45)$ & $(0.46,0.48,0.5)$ & $(6.1,6.49,6.88)$ \\
\hline $\mathrm{Cm} 8$ & $(6.6,7)$ & 8.4) & $(0.28,0.31,0.34)$ & $(0.4,0.43,0.46)$ & $(7.43,7.9,8.37)$ \\
\hline
\end{tabular}

After considering the selection criteria, the criteria weights were calculated using the BWM method (Table 5). These weights are determined based on the opinion of experts (Supplementary Table 1). In this study, five experts were selected from different backgrounds related to the coating material application.

According to the methodology, the best and worst criteria were initially identified, and pairwise comparison was performed. The selection of the best and worst criteria was based on a questionnaire in which experts were involved. The final criteria weights and inconsistency rate are 
tabulated in Table 4, where the inconsistency rate is 0.048 , which is nearer to zero $(0)$. It can be extended to 5.23 (under consistency index Table 4). Hence, it can be said that the pairwise comparison is more consistent.

Table 4 Weight of criteria and inconsistency rate (Ksi*)

\begin{tabular}{|l|c|c|c|c|c|c|c|c|c|}
\hline Criteria & $\mathrm{C}_{1}$ & $\mathrm{C}_{2}$ & $\mathrm{C}_{3}$ & $\mathrm{C}_{4}$ & $\mathrm{C}_{5}$ & $\mathrm{C}_{6}$ & $\mathrm{C}_{7}$ & $\mathrm{C}_{8}$ & $\mathrm{C}_{9}$ \\
\hline Weight & 0.254 & 0.151 & 0.076 & 0.061 & 0.152 & 0.027 & 0.1 & 0.076 & 0.103 \\
\hline Ksi* & 0.048 & \\
\hline
\end{tabular}

\subsection{Rank evaluation of the alternatives using fuzzy-MARCOS approach}

Before normalizing the initial fuzzy decision matrix, the ideal $(A I)$ and anti-ideal solution $(A A I)$ need to be calculated for each alternative corresponding to each criterion. $A I$ was the highest value of each criterion, while the lowest value was the $A A I$ concerning each alternative. Next, with the help of Eq. (14) and Eq. (15) of the fuzzy-MARCOS method, the value of the initial fuzzy decision matrix was normalized (Supplementary Table 2). In the third step, the value of criteria weights was multiplied by the corresponding element of the fuzzy normalized matrix to obtain the weighted fuzzy normalized matrix (Supplementary Table 3). In the next step, the value of $\tilde{S}_{i}$ each alternative was determined using Eq. (17). Similarly, the total weighted value for an ideal and antiideal solution was calculated respectively (Supplementary Table 3). The fourth step was dealing with the calculation of the utility degree of the alternative using Eq. (18) and Eq. (19), respectively (Table 5).

New fuzzy numbers $\tilde{d}$ and defuzzified values $d f_{\text {crisp }}$ were calculated to obtain the value of $f\left(\tilde{K}_{i}^{-}\right)$and $f\left(\tilde{K}_{i}^{+}\right)$. Using Eq. (23) and Eq. (24), the utility function value of each alternative was calculated (Table 6). The final utility function value of alternatives was calculated using Eq. (25). Using these values, a ranking of alternatives was derived.

The evaluated results showed alternative $\mathrm{Cm}_{7}$ is the best alternative of coating material for tooling application while $\mathrm{Cm}_{1}$ is the worst alternative (Supplementary Table 2). the order of the alternative is $\mathrm{Cm}_{2}<\mathrm{Cm}_{1}<\mathrm{Cm}_{6}<\mathrm{Cm}_{4}<\mathrm{Cm}_{3}<\mathrm{Cm}_{8}<\mathrm{Cm}_{7}<\mathrm{Cm}_{5}$ in ascending order of value of utility function. 
Table 5 Calculating and summarizing the utility degree and fuzzy matrix of $\tilde{t}_{i}$

\begin{tabular}{|c|c|c|c|c|}
\hline Alternative & $\tilde{S}_{i}$ & $\tilde{K}_{i}^{-}$ & $\tilde{K}_{i}^{+}$ & $\tilde{t}_{i}$ \\
\hline$A A I$ & $(0.487,0.528,0.570)$ & & & \\
\hline $\mathrm{Cm}_{1}$ & $(0.571,0.617,0.664)$ & $(1.003,1.169,1.365)$ & $(0.571,0.659,0.758)$ & $(1.574,1.828,2.123)$ \\
\hline $\mathrm{Cm}_{2}$ & $(0.548,0.593,0.639)$ & $(0.962,1.123,1.313)$ & $(0.548,0.633,0.729)$ & $(1.511,1.757,2.041)$ \\
\hline $\mathrm{Cm}_{3}$ & $(0.717,0.780,0.848)$ & $(1.258,1.478,1.742)$ & $(0.717,0.833,0.967)$ & $(1.974,2.311,2.709)$ \\
\hline $\mathrm{Cm}_{4}$ & $(0.638,0.706,0.778)$ & $(1.120,1.338,1.599)$ & $(0.638,0.754,0.888)$ & $(1.758,2.092,2.487)$ \\
\hline $\mathrm{Cm}_{5}$ & $(0.801,0.853,0.908)$ & $(1.405,1.616,1.865)$ & $(0.801,0.911,1.035)$ & $(2.206,2.527,2.900)$ \\
\hline $\mathrm{Cm}_{6}$ & $(0.649,0.700,0.757)$ & $(1.140,1.325,1.555)$ & $(0.649,0.747,0.863)$ & $(1.789,2.073,2.419)$ \\
\hline $\mathrm{Cm}_{7}$ & $(0.786,0.834,0.885)$ & $(1.379,1.580,1.818)$ & $(0.786,0.891,1.009)$ & $(2.165,2.471,2.827)$ \\
\hline $\mathrm{Cm}_{8}$ & $(0.725,0.796,0.871)$ & $(1.273,1.508,1.790)$ & $(0.725,0.850,0.994)$ & $(1.998,2.358,2.784)$ \\
\hline$A I$ & $(0.877,0.936,1.000)$ & & & $d f_{\text {crisp }}=2.536$ \\
\hline
\end{tabular}

Table 6 Values of utility functions and final ranking of the alternatives

\begin{tabular}{|c|c|c|c|c|c|c|c|c|}
\hline Alternative & $f\left(\tilde{K}_{i}^{-}\right)$ & $f\left(\tilde{K}_{i}^{+}\right)$ & $K_{i}^{-}$ & $K_{i}^{+}$ & $f\left(K_{i}^{-}\right)$ & $f\left(K_{i}^{+}\right)$ & $f\left(K_{i}\right)$ & Rank \\
\hline $\mathrm{Cm}_{1}$ & $(0.225,0.260,0.299)$ & $(0.395,0.461,0.538)$ & 1.174 & 0.661 & 0.261 & 0.463 & 0.145 & 7 \\
\hline $\mathrm{Cm}_{2}$ & $(0.216,0.250,0.287)$ & $(0.379,0.443,0.518)$ & 1.128 & 0.635 & 0.250 & 0.445 & 0.133 & 8 \\
\hline $\mathrm{Cm}_{3}$ & $(0.283,0.329,0.381)$ & $(0.496,0.583,0.687)$ & 1.485 & 0.836 & 0.330 & 0.586 & 0.245 & 4 \\
\hline $\mathrm{Cm}_{4}$ & $(0.252,0.297,0.350)$ & $(0.442,0.527,0.631)$ & 1.345 & 0.757 & 0.299 & 0.530 & 0.196 & 5 \\
\hline $\mathrm{Cm}_{5}$ & $(0.316,0.359,0.408)$ & $(0.554,0.637,0.735)$ & 1.622 & 0.913 & 0.360 & 0.640 & 0.299 & 1 \\
\hline $\mathrm{Cm}_{6}$ & $(0.256,0.295,0.340)$ & $(0.449,0.523,0.613)$ & 1.333 & 0.750 & 0.296 & 0.526 & 0.192 & 6 \\
\hline $\mathrm{Cm}_{7}$ & $(0.310,0.351,0.398)$ & $(0.544,0.623,0.717)$ & 1.586 & 0.893 & 0.352 & 0.626 & 0.284 & 2 \\
\hline $\mathrm{Cm}_{8}$ & $(0.286,0.335,0.392)$ & $(0.502,0.595,0.706)$ & 1.516 & 0.853 & 0.336 & 0.598 & 0.256 & 3 \\
\hline
\end{tabular}

\section{Sensitivity analysis}

This section tested and validated the obtained result of the proposed integrated fuzzy-MADM method by performing the sensitivity analysis. In this analysis, four-step procedures have been followed, and these procedures are (i) effect of criteria weight change on the ranking, (ii) effect of criteria weight derived from other methods, (iii) effect of dynamic matrices on the ranking, and (iv) comparison with other well established MADM methods. Not only this, the proposed 
integrated fuzzy-MADM method is tested by solving the different published results for coating material selection.

\subsection{Effect of criteria weight change on the ranking of alternatives}

In this analysis, a change in criteria weight was considered to observe how the ranking of alternatives reacts concerning weight change (Puška et al. 2018). In the present study, seven different criteria weight scenarios were considered to perform this analysis (Table 7). The weights of the first five scenarios were determined using the BWM method by changing the preferences. In the sixth scenario, weight was equally distributed, while in the seventh scenario, half (0.5) of criteria weight was assigned to criteria $C_{1}$ and the remaining $(0.0625)$ equally distributed among other criteria. The ranking of the alternatives was derived using proposed MADM methods with these seven different criteria weights (Fig. 2).

Table 7 Different Scenario of criteria weightage for sensitivity analysis.

\begin{tabular}{|c|c|c|c|c|c|c|c|c|c|}
\hline \multirow{2}{*}{ Scenarios } & \multicolumn{10}{|c|}{ Criteria weightage } \\
\cline { 2 - 10 } & $\mathrm{C}_{1}$ & $\mathrm{C}_{2}$ & $\mathrm{C}_{3}$ & $\mathrm{C}_{4}$ & $\mathrm{C}_{5}$ & $\mathrm{C}_{6}$ & $\mathrm{C}_{7}$ & $\mathrm{C}_{8}$ & $\mathrm{C}_{9}$ \\
\hline Scenario 1 $\left(\mathrm{S}_{1}\right)$ & 0.254 & 0.151 & 0.076 & 0.061 & 0.152 & 0.027 & 0.1 & 0.076 & 0.103 \\
\hline Scenario 2 $\left(\mathrm{S}_{2}\right)$ & 0.149 & 0.138 & 0.078 & 0.066 & 0.284 & 0.020 & 0.062 & 0.080 & 0.123 \\
\hline Scenario 3 $\left(\mathrm{S}_{3}\right)$ & 0.110 & 0.039 & 0.055 & 0.190 & 0.094 & 0.068 & 0.300 & 0.047 & 0.097 \\
\hline Scenario 4 $\left(\mathrm{S}_{4}\right)$ & 0.110 & 0.018 & 0.087 & 0.190 & 0.019 & 0.038 & 0.400 & 0.078 & 0.060 \\
\hline Scenario 5 $\left(\mathrm{S}_{5}\right)$ & 0.016 & 0.018 & 0.099 & 0.190 & 0.019 & 0.038 & 0.400 & 0.160 & 0.060 \\
\hline Scenario 6 $\left(\mathrm{S}_{6}\right)$ & 0.111 & 0.111 & 0.111 & 0.111 & 0.111 & 0.111 & 0.111 & 0.111 & 0.111 \\
\hline Scenario 7 $\left(\mathrm{S}_{7}\right)$ & 0.500 & 0.063 & 0.063 & 0.063 & 0.063 & 0.063 & 0.063 & 0.063 & 0.063 \\
\hline
\end{tabular}




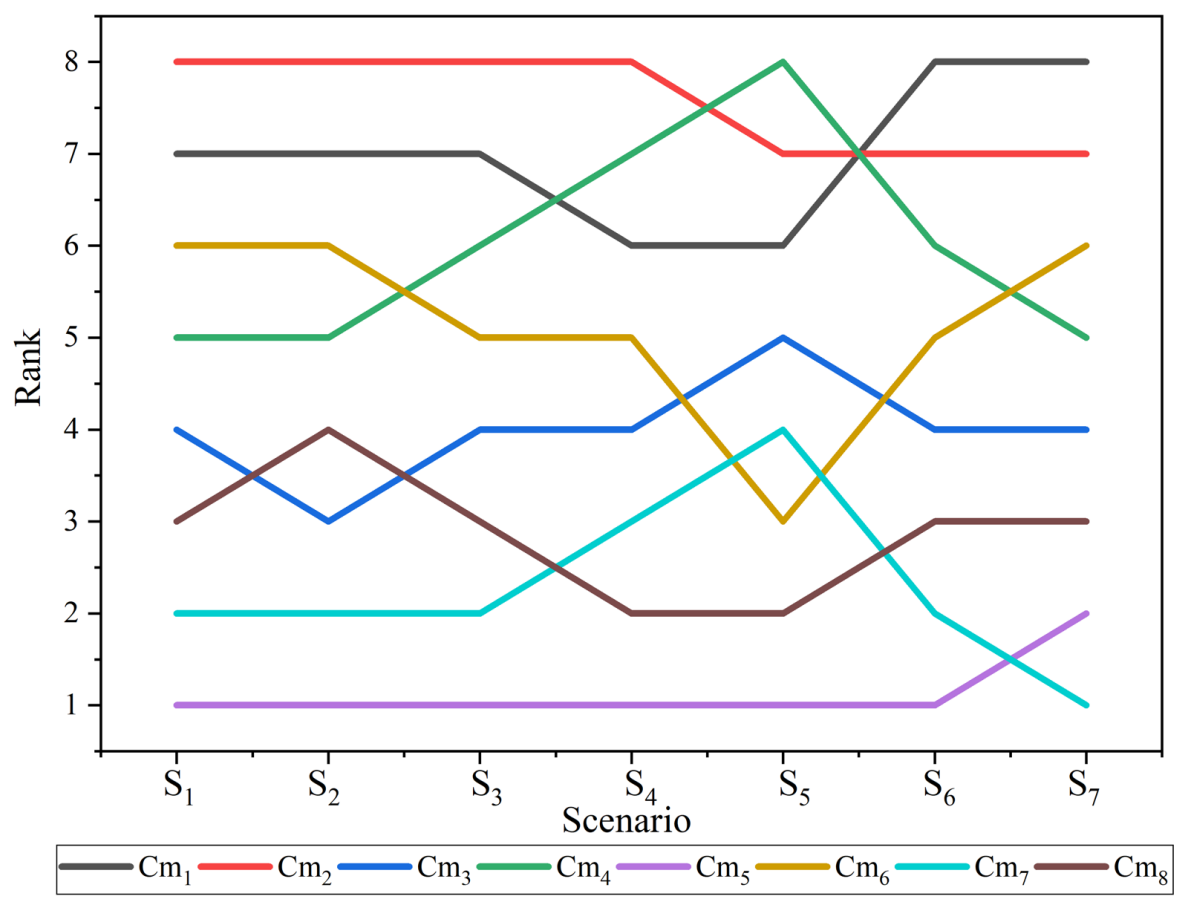

Fig. 2 Ranking of alternatives for seven different scenarios

The obtained results showed that the ranking of alternatives is changing with respect to the criteria weight change. It confirms that the proposed MADM methodology is sensitive to the criteria weight change. The evaluation of obtained results suggests that $\mathrm{Cm}_{5}$ remains the best alternative for six scenarios while it is the second-best alternative for the $7^{\text {th }}$ scenario. It is sufficient enough to conclude that $\mathrm{Cm}_{5}$ is the best coating material alternative. Additionally, $\mathrm{Cm}_{1}$ is the worst alternative for the first four scenarios $\left(\mathrm{S}_{1}, \mathrm{~S}_{2}, \mathrm{~S}_{3}\right.$, and $\left.\mathrm{S}_{4}\right)$, while it is the second worst alternative for the last three scenarios $\left(\mathrm{S}_{5}, \mathrm{~S}_{6}\right.$, and $\left.\mathrm{S}_{7}\right)$. The ranking obtained during the sensitivity test was also assisted by Spearman's rank correlation coefficient between the original rank and ranking obtained from each scenario. The rank correlation coefficient values for each scenario are more than 0.91 , and the mean value is 0.97 . It shows a stronger correlation between ranks and credibility of the integrated BWM fuzzy-MARCOS method.

\subsection{Effect of dynamic matrices on the ranking of alternatives}

Substituting some parameters of the initial fuzzy decision matrix, such as removing the existing alternative or introducing a new alternative, can change the ranking of alternatives. In this section, several scenarios were formed by removing the existing initial fuzzy decision matrix alternative to simulate the performance. For each scenario, a new initial fuzzy decision matrix was created by removing the existing alternative, and then the proposed MADM method was applied. 
In this condition, the worst alternative of the existing matrix, i.e., $\mathrm{Cm}_{2}$ $\left(\mathrm{Cm}_{2}<\mathrm{Cm}_{1}<\mathrm{Cm}_{6}<\mathrm{Cm}_{4}<\mathrm{Cm}_{3}<\mathrm{Cm}_{8}<\mathrm{Cm}_{7}<\mathrm{Cm}_{5}\right)$ was eliminated to create a new initial fuzzy decision matrix with seven alternatives. Then the new solution was obtained as follows: $\mathrm{Cm}_{1}<\mathrm{Cm}_{6}<\mathrm{Cm}_{4}<\mathrm{Cm}_{3}<\mathrm{Cm}_{8}<\mathrm{Cm}_{7}<\mathrm{Cm}_{5} . \mathrm{Cm}_{1}$ was identified as the worst alternative for the next scenario, and it was removed to create a new initial fuzzy decision matrix. Similarly, a total of seven scenarios were created, and the obtained result is presented in Fig. 3 (a).

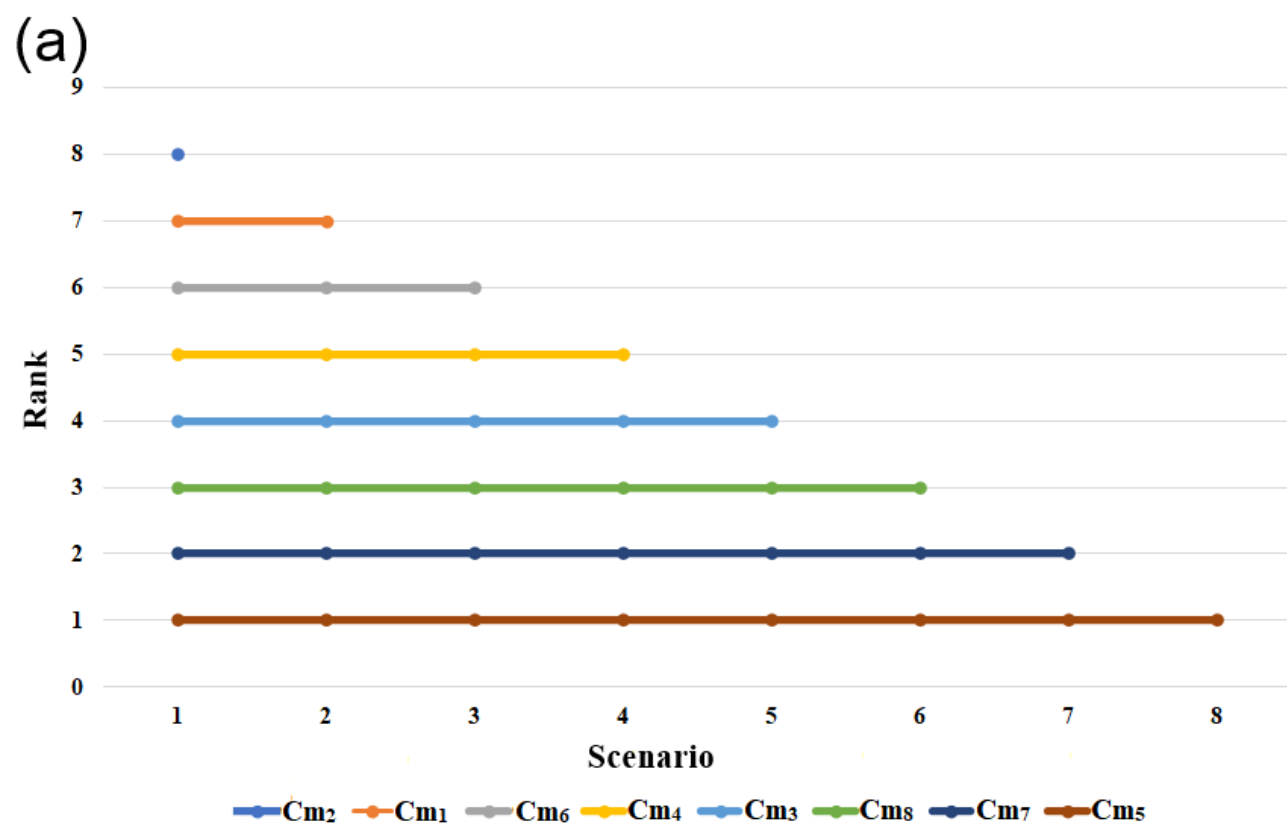

(b)

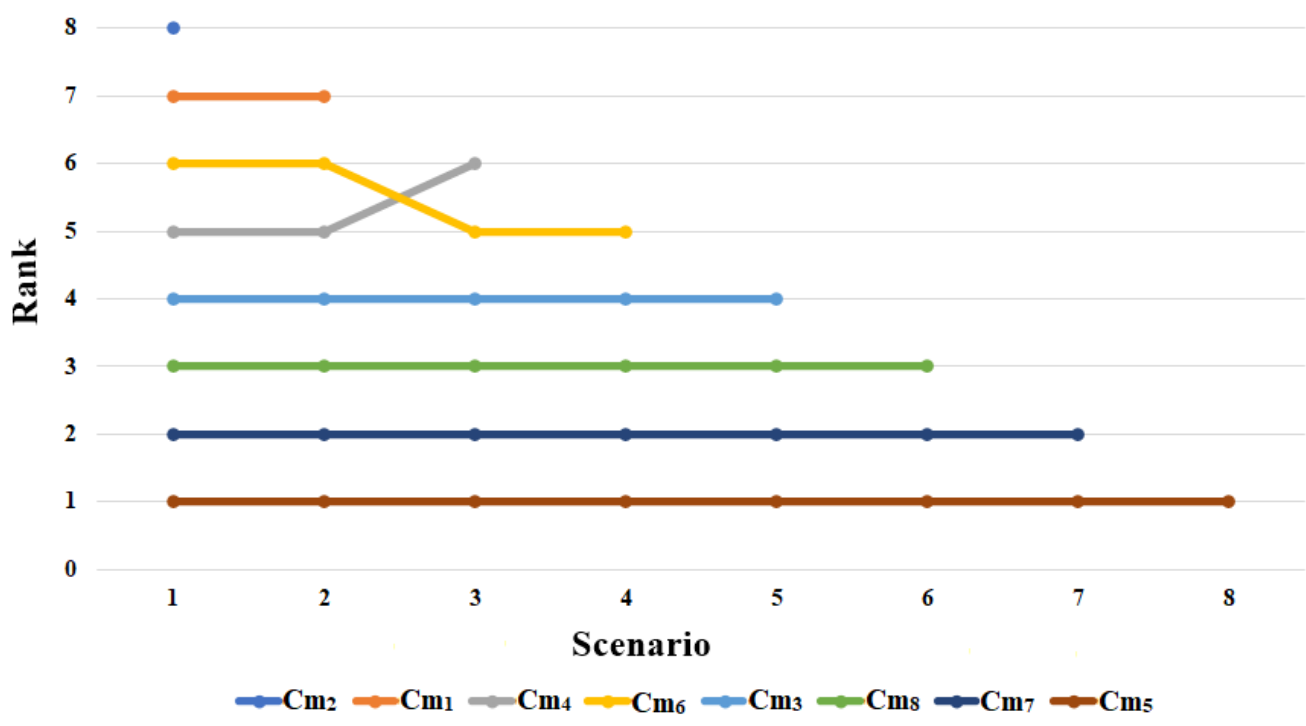

Fig. 3 Effect of dynamic matrices on the ranking of alternatives 
In the fuzzy-MARCOS algorithm, alternatives are examined based on ideal and anti-ideal reference points. The fuzzy-TOPSIS algorithm uses a similar concept to examine the alternatives. So, the effect of dynamic matrices was performed by both the methods (fuzzy-TOPSIS and fuzzyMARCOS). Figure 3 (b), shows that for scenarios $S_{3}-S_{4}$, the rank of $6^{\text {th }}$ alternative $\left(\mathrm{Cm}_{6}\right)$ changes to fifth position (rank reversal). At the same time, there is no such change observed for the fuzzyMARCOS method when the initial fuzzy decision matrix was modified (Fig. 3(a)). From both the MADM method, $\mathrm{Cm}_{5}$ is the best alternative for all the scenarios. It indicates the stability and robustness of the integrated BWM fuzzy-MARCOS method in dynamic conditions.

\subsection{Effect of criteria weights derived by different weighting methods}

In this phase, criteria weights were derived using different weighing methods (Entropy (Alao et al. 2020), Standard deviation (Anitha et al. 2020), AHP (Ho 2008), CRITIC (Peng et al. 202) and MEREC (Keshavarz-Ghorabaee et al. 2021). Then these weights are combined with fuzzyMARCOS to determine the preference rating of the alternatives to compare the obtained results of the proposed BWM integrated fuzzy-MADM method. The derived criteria weights are tabulated in Table 8, and the corresponding results are presented in Fig. 4.

Table 8 Criteria weights derived by different weighing method

\begin{tabular}{|c|c|c|c|c|c|c|c|c|c|}
\hline Weighing methods & $\mathrm{C}_{1}$ & $\mathrm{C}_{2}$ & $\mathrm{C}_{3}$ & $\mathrm{C}_{4}$ & $\mathrm{C}_{5}$ & $\mathrm{C}_{6}$ & $\mathrm{C}_{7}$ & $\mathrm{C}_{8}$ & $\mathrm{C}_{9}$ \\
\hline Entropy & 0.091 & 0.008 & 0.068 & 0.119 & 0.026 & 0.055 & 0.494 & 0.060 & 0.080 \\
\hline STDEV & 0.125 & 0.113 & 0.112 & 0.113 & 0.113 & 0.085 & 0.112 & 0.118 & 0.109 \\
\hline AHP & 0.241 & 0.092 & 0.081 & 0.141 & 0.125 & 0.035 & 0.173 & 0.064 & 0.048 \\
\hline CRITIC & 0.089 & 0.082 & 0.087 & 0.085 & 0.082 & 0.148 & 0.154 & 0.191 & 0.084 \\
\hline MEREC & 0.115 & 0.030 & 0.103 & 0.089 & 0.052 & 0.090 & 0.325 & 0.078 & 0.117 \\
\hline
\end{tabular}




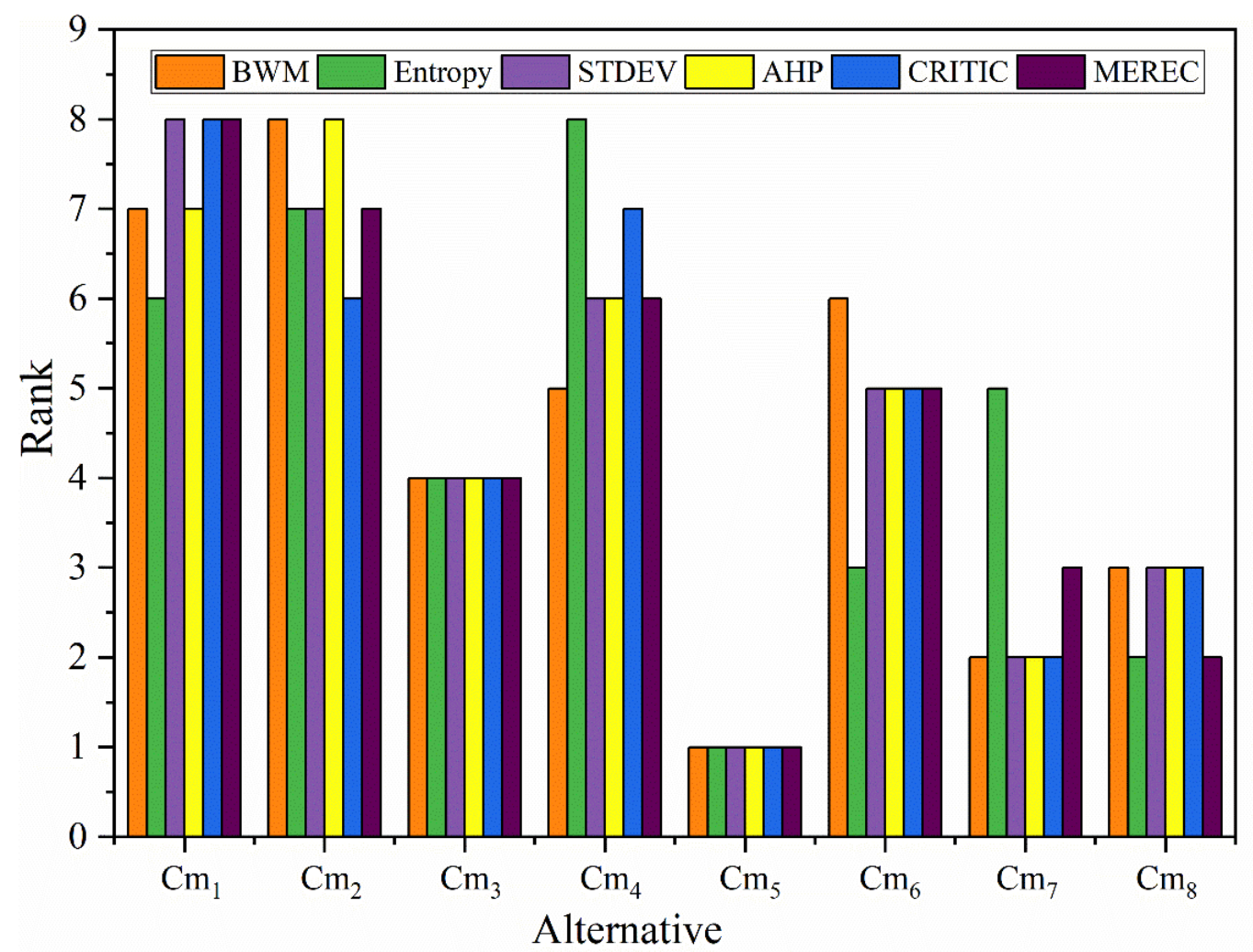

Fig.4 Effect of different criteria weighting methods on the ranking of alternative

From comparative analysis (Fig. 4), $\mathrm{Cm}_{5}$ is observed as the best coating alternative from all the selected weighing methods integrated with the fuzzy-MARCOS method. It is similar to the ranking position obtained by the BWM integrated fuzzy-MARCOS method. In addition to this, the ranking of alternative $\mathrm{Cm}_{3}$ does not change, while minor changes can be seen in the ranking of other alternatives, which did not affect the overall results. These changes in the ranking might be attributed to the different theoretical structures of weighing methods. The BWM method has a different procedure than the other weighing method, and it is based on linear programming (Rezaei et al. 2015), which help the researcher to the quick generation of criteria weight. It is also a less time-consuming method to derive the criteria weight. In this perspective, BWM can contribute a more relevant and convenient algorithm than can be used by the researcher. Spearman's rank correlation coefficient analyzed the correlation between the selected weighing methods and the proposed BWM method. The correlation coefficient between all the methods was found more than 0.93 except BWM and Entropy method (0.65). These findings indicate all the methods are strongly correlated to each other. 


\subsection{Comparison with other MADM methods}

In this phase of sensitivity analysis, six different integrated fuzzy-MADM methods were considered to check the result obtained by the fuzzy-MARCOS method. The considered MADM methods are fuzzy-WASPAS (Turskis et al. 2015), fuzzy-COPRAS (Alkan et al. 2020), fuzzyMABAC (Liang et al. 2019), fuzzy-CODAS (Yalçın et al. 2019), fuzzy-EDAS (Polat et al. 2020) and fuzzy-TOPSIS (Maity et al. 2013). During the evaluation of the performance rating of alternative, same criteria weights were used as it was used for fuzzy-MARCOS method and the obtained results presented in Fig. 5.

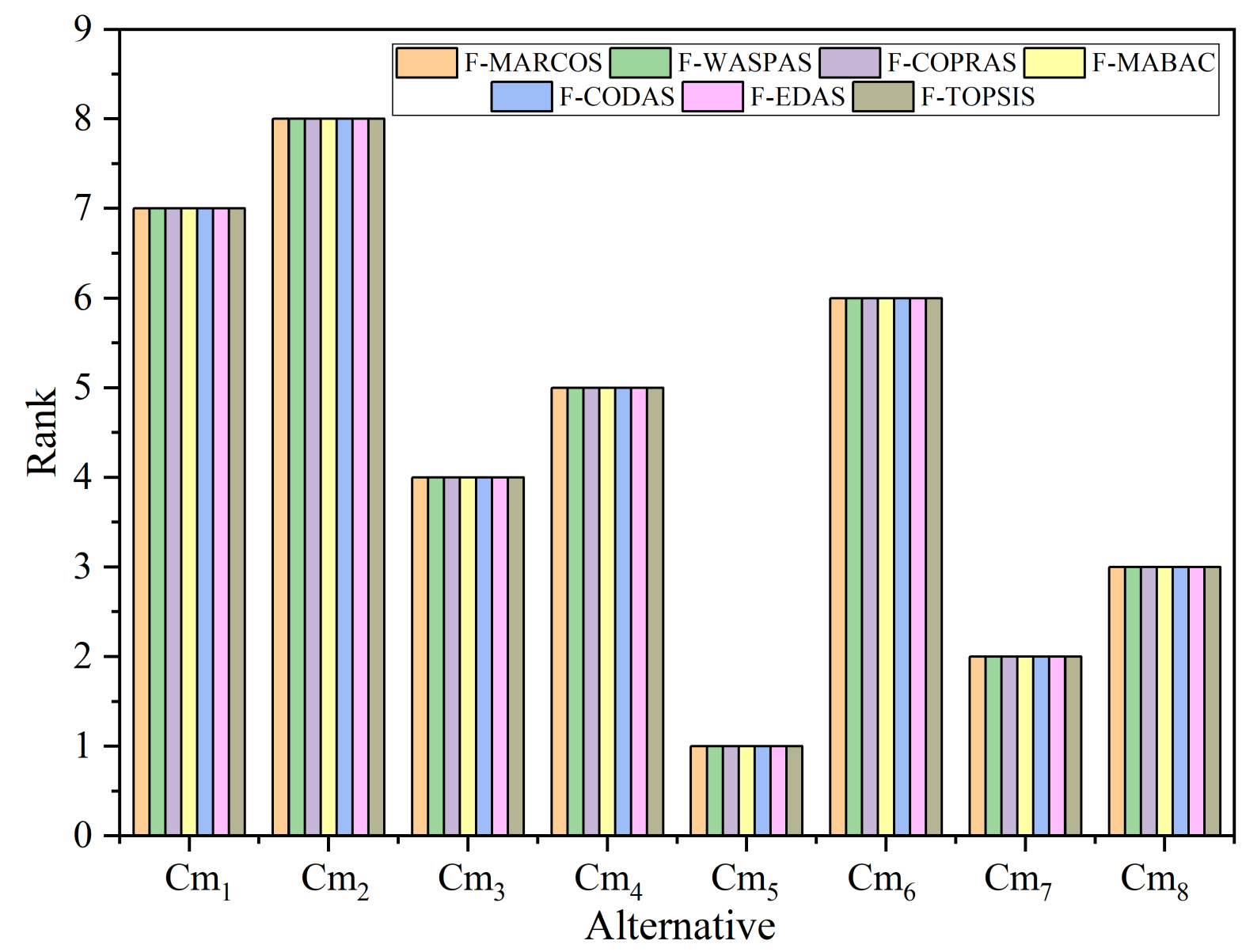

Fig. 5 Ranking of alternative using different MADM methods

The obtained results from different MADM methods show there is no difference in the ranking of the best alternative, $\mathrm{Cm}_{5}(\mathrm{AlCrN} / \mathrm{TiAlN})$ (Fig. 5). There is also no change in the ranking of other alternatives except $\mathrm{Cm}_{1}$. Alternative $\mathrm{Cm}_{1}$ has allotted the eighth rank by fuzzy-TOPSIS method while other methods are given the seventh rank. This minor change does not affect the 
overall results of this study. Similar results obtained by all the MADM methods confirm the result obtained by the fuzzy-MARCOS method. Hence, it proved that the proposed integrated BWM fuzzy-MARCOS approach could be used to solve this type of problem.

\subsection{Other coating material selection problems were solved using the integrated BWM fuzzy-MARCOS approach}

This section deals with the problem solving by the fuzzy-MARCOS method for other coating material selection, which past researchers have solved. This section has taken three different coating material selection problems that were solved using different MADM methods. The first example was for hard coating material selection. The second was to solve the coating material selection to enhance the heat transfer performance. The third was to solve a coating material selection problem for magnesium alloy.

\subsubsection{Hard coating material selection}

Chauhan and Vaish (Chauhan et al. 2013) have been adopted the TOPSIS approach to solving the hard coating material selection problem. The other researcher also solved this coating material selection problem using COPRAS and WASPAS approaches (Petković et al. 2021). Table 1 of the reference paper (Chauhan et al. 2013) demonstrates the alternative and selection criteria of the hard coating.

All the demonstrated criteria are beneficial criteria except thermal expansion coefficient, and it is non-beneficial criteria. The obtained criteria weights using BWM method are $w_{C 1}=0.417$, $w_{C 2}=0.167, w_{C 3}=0.25, w_{C 4}=0.125$ and $w_{C 5}=0.042$. The performance evaluation of the alternative was done using the fuzzy-MARCOS method (section 3.2.2), and the results are presented in Table 9. 
Table 9 The final preference value of alternative and its ranking

\begin{tabular}{|c|c|c|c|c|c|c|c|c|c|c|c|}
\hline Alternative & $f\left(K_{i}\right)$ & F-MARCOS & $\begin{array}{c}\text { TOPSIS } \\
\text { (Chauhan } \\
\text { et al. } \\
\text { 2013) }\end{array}$ & $\begin{array}{c}\text { COPRAS } \\
\text { (Petković } \\
\text { et al. } \\
\text { 2013) }\end{array}$ & $\begin{array}{c}\text { WASPAS } \\
\text { (Petković } \\
\text { et al. } \\
\text { 2013) }\end{array}$ & Alternative & $f\left(K_{i}\right)$ & F-MARCOS & $\begin{array}{c}\text { TOPSIS } \\
\text { (Chauhan } \\
\text { et al. } \\
\text { 2013) }\end{array}$ & $\begin{array}{c}\text { COPRAS } \\
\text { (Petković } \\
\text { et al. } \\
\text { 2013) }\end{array}$ & $\begin{array}{c}\text { WASPAS } \\
\text { (Petković } \\
\text { et al. } \\
\text { 2013) }\end{array}$ \\
\hline $\mathrm{Cm}_{1}$ & 0.123 & 1 & 1 & 1 & 1 & $\mathrm{Cm}_{20}$ & 0.014 & 18 & 20 & 19 & 19 \\
\hline $\mathrm{Cm}_{2}$ & 0.056 & 2 & 2 & 2 & 2 & $\mathrm{Cm}_{21}$ & 0.006 & 33 & 21 & 32 & 33 \\
\hline $\mathrm{Cm}_{3}$ & 0.034 & 3 & 3 & 3 & 3 & $\mathrm{Cm}_{22}$ & 0.010 & 25 & 22 & 26 & 28 \\
\hline $\mathrm{Cm}_{4}$ & 0.018 & 11 & 4 & 4 & 5 & $\mathrm{Cm}_{23}$ & 0.014 & 16 & 23 & 20 & 18 \\
\hline $\mathrm{Cm}_{5}$ & 0.024 & 4 & 5 & 5 & 4 & $\mathrm{Cm}_{24}$ & 0.010 & 24 & 24 & 25 & 24 \\
\hline $\mathrm{Cm}_{6}$ & 0.019 & 9 & 6 & 6 & 7 & $\mathrm{Cm}_{25}$ & 0.012 & 22 & 25 & 23 & 22 \\
\hline $\mathrm{Cm}_{7}$ & 0.020 & 8 & 7 & 7 & 9 & $\mathrm{Cm}_{26}$ & 0.004 & 36 & 26 & 36 & 36 \\
\hline $\mathrm{Cm} 8$ & 0.020 & 7 & 8 & 8 & 10 & $\mathrm{Cm}_{27}$ & 0.014 & 20 & 27 & 22 & 21 \\
\hline $\mathrm{Cm}_{9}$ & 0.018 & 12 & 9 & 11 & 11 & $\mathrm{Cm}_{28}$ & 0.009 & 27 & 28 & 27 & 27 \\
\hline $\mathrm{Cm}_{10}$ & 0.021 & 6 & 10 & 10 & 8 & $\mathrm{Cm}_{29}$ & 0.007 & 31 & 29 & 33 & 32 \\
\hline $\mathrm{Cm}_{11}$ & 0.022 & 5 & 11 & 9 & 6 & $\mathrm{Cm}_{30}$ & 0.008 & 28 & 30 & 29 & 29 \\
\hline $\mathrm{Cm}_{12}$ & 0.019 & 10 & 12 & 12 & 12 & $\mathrm{Cm}_{31}$ & 0.012 & 23 & 31 & 24 & 23 \\
\hline $\mathrm{Cm}_{13}$ & 0.015 & 15 & 13 & 13 & 13 & $\mathrm{Cm}_{32}$ & 0.009 & 26 & 32 & 28 & 26 \\
\hline $\mathrm{Cm}_{14}$ & 0.006 & 34 & 14 & 18 & 25 & $\mathrm{Cm}_{33}$ & 0.008 & 30 & 33 & 31 & 30 \\
\hline $\mathrm{Cm}_{15}$ & 0.014 & 17 & 15 & 16 & 16 & $\mathrm{Cm}_{34}$ & 0.008 & 29 & 34 & 30 & 31 \\
\hline $\mathrm{Cm}_{16}$ & 0.017 & 14 & 16 & 15 & 15 & $\mathrm{Cm}_{35}$ & 0.005 & 35 & 35 & 35 & 35 \\
\hline $\mathrm{Cm}_{17}$ & 0.014 & 19 & 17 & 17 & 17 & $\mathrm{Cm}_{36}$ & 0.007 & 32 & 36 & 34 & 34 \\
\hline $\mathrm{Cm}_{18}$ & 0.018 & 13 & 18 & 14 & 14 & $\mathrm{Cm}_{37}$ & 0.003 & 37 & 37 & 37 & 37 \\
\hline $\mathrm{Cm}_{19}$ & 0.013 & 21 & 19 & 21 & 20 & & & & & & \\
\hline
\end{tabular}


The obtained results (Table 9) noticed that $C_{m 1}$ is the best alternative while $C_{m 37}$ is the worst coating alternative, and this ranking exactly matched with the ranking obtained by the past study. Further, Spearman's rank correlation coefficient between the proposed approach and the existing approach was determined. The obtained average coefficient value (0.9) suggests that these approaches are strongly correlated. Hence, the obtained results are acceptable.

Additionally, sensitivity analysis was performed to validate the obtained results, and this analysis has three phases as is discussed in sections 5.1, 5.2, 5.3, and 5.4. Even though the ranking of some alternatives is changed according to the different scenarios, the best and worst alternative ranking does not change. It indicates the stability and reliability of the proposed BWM fuzzyMARCOS method. Effect of criteria weight change on the ranking is represented in Fig. 6(a), while the dynamic matrices effect is shown in Fig. 6(b). Figure 6(c) shows the effect of different criteria weight calculation methods on the ranking of alternatives, whereas Fig. 6(d) represents the ranking of alternatives derived from BWM integrated different fuzzy-MADM methods. Furthermore, it observed that the sensitivity analysis rankings have an excellent correlation between them as the average Spearman's rank correlation coefficient is 0.98 .

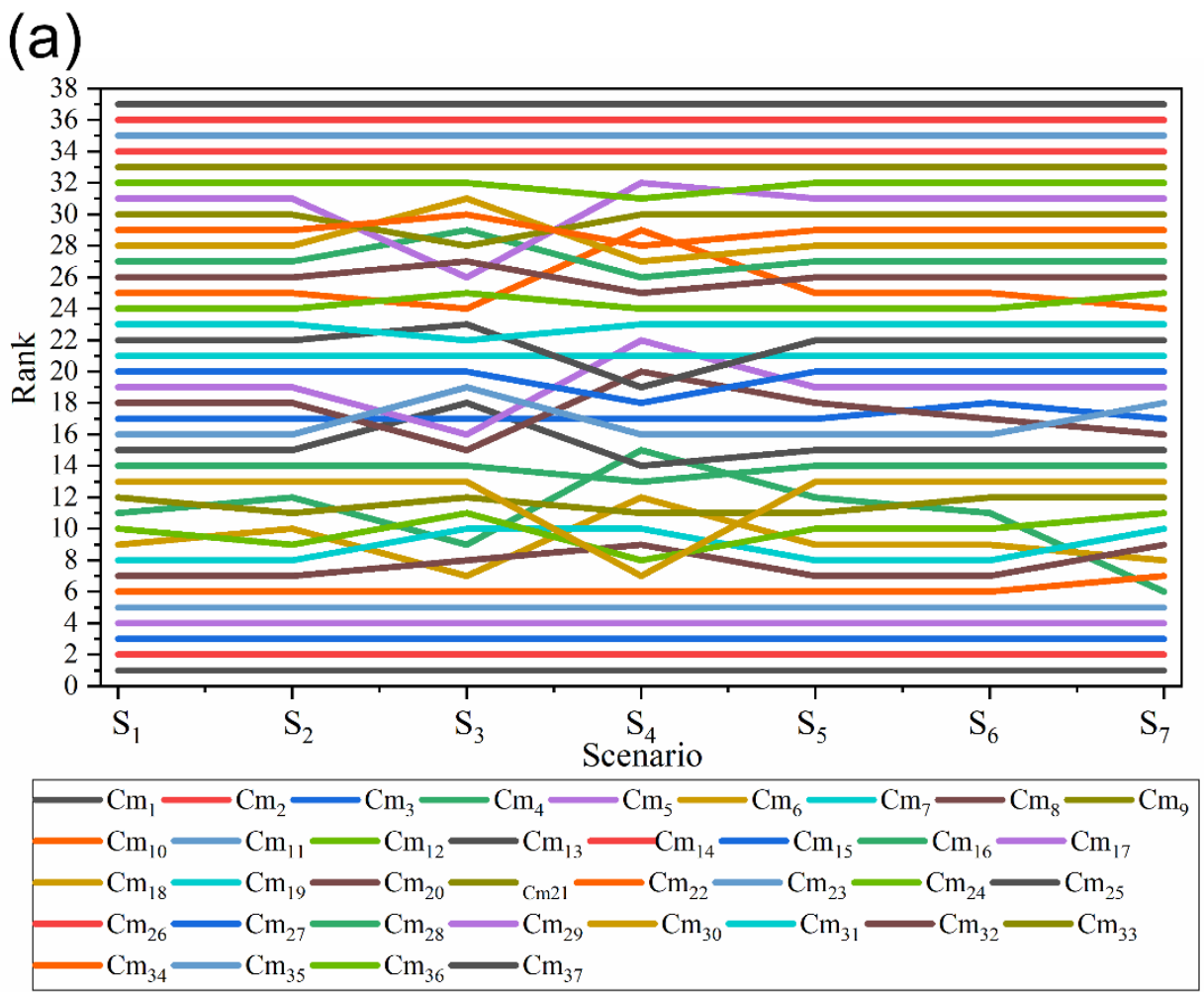




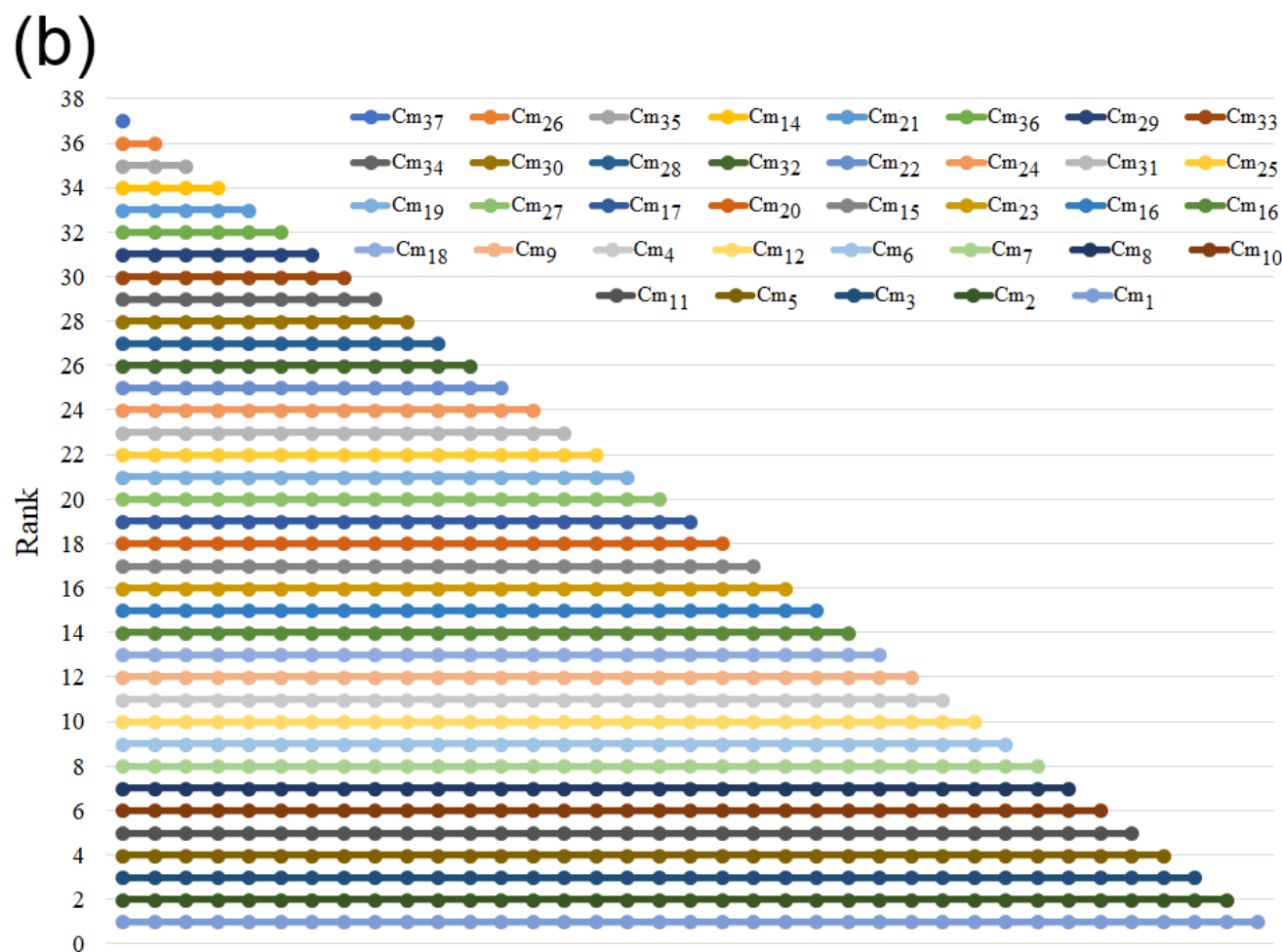

$122 \quad 3 \quad 4 \quad 5 \quad 6 \quad 7 \quad 8 \quad 910111213141516171819202122232425262728293031323334353637$

Scenario

(c)

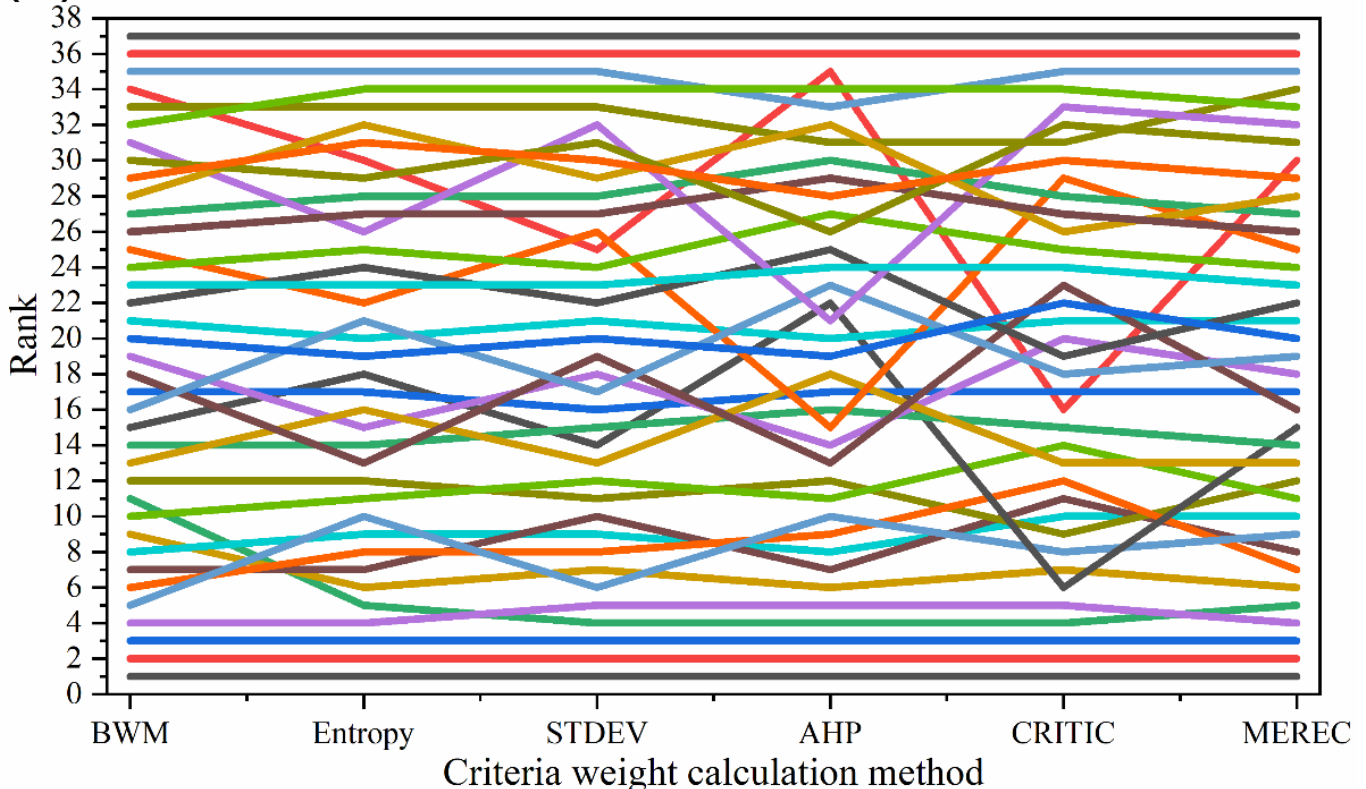

\begin{tabular}{|l}
\hline $\mathrm{Cm}_{1}-\mathrm{Cm}_{2}-\mathrm{Cm}_{3}-\mathrm{Cm}_{4}-\mathrm{Cm}_{5}-\mathrm{Cm}_{6}-\mathrm{Cm}_{7}-\mathrm{Cm}_{8}-\mathrm{Cm}_{9}$ \\
$\mathrm{Cm}_{10}-\mathrm{Cm}_{11}-\mathrm{Cm}_{12}-\mathrm{Cm}_{13}-\mathrm{Cm}_{14}-\mathrm{Cm}_{15}-\mathrm{Cm}_{16}-\mathrm{Cm}_{17}$ \\
$\mathrm{Cm}_{18}-\mathrm{Cm}_{19}-\mathrm{Cm}_{20}-\mathrm{Cm}_{21}-\mathrm{Cm}_{22}-\mathrm{Cm}_{23}-\mathrm{Cm}_{24}-\mathrm{Cm}_{25}$ \\
$\mathrm{Cm}_{26}-\mathrm{Cm}_{27}-\mathrm{Cm}_{28}-\mathrm{Cm}_{29}-\mathrm{Cm}_{30}-\mathrm{Cm}_{31}-\mathrm{Cm}_{32}-\mathrm{Cm}_{33}$ \\
$\mathrm{Cm}_{34}-\mathrm{Cm}_{35}-\mathrm{Cm}_{36}-\mathrm{Cm}_{37}$
\end{tabular}




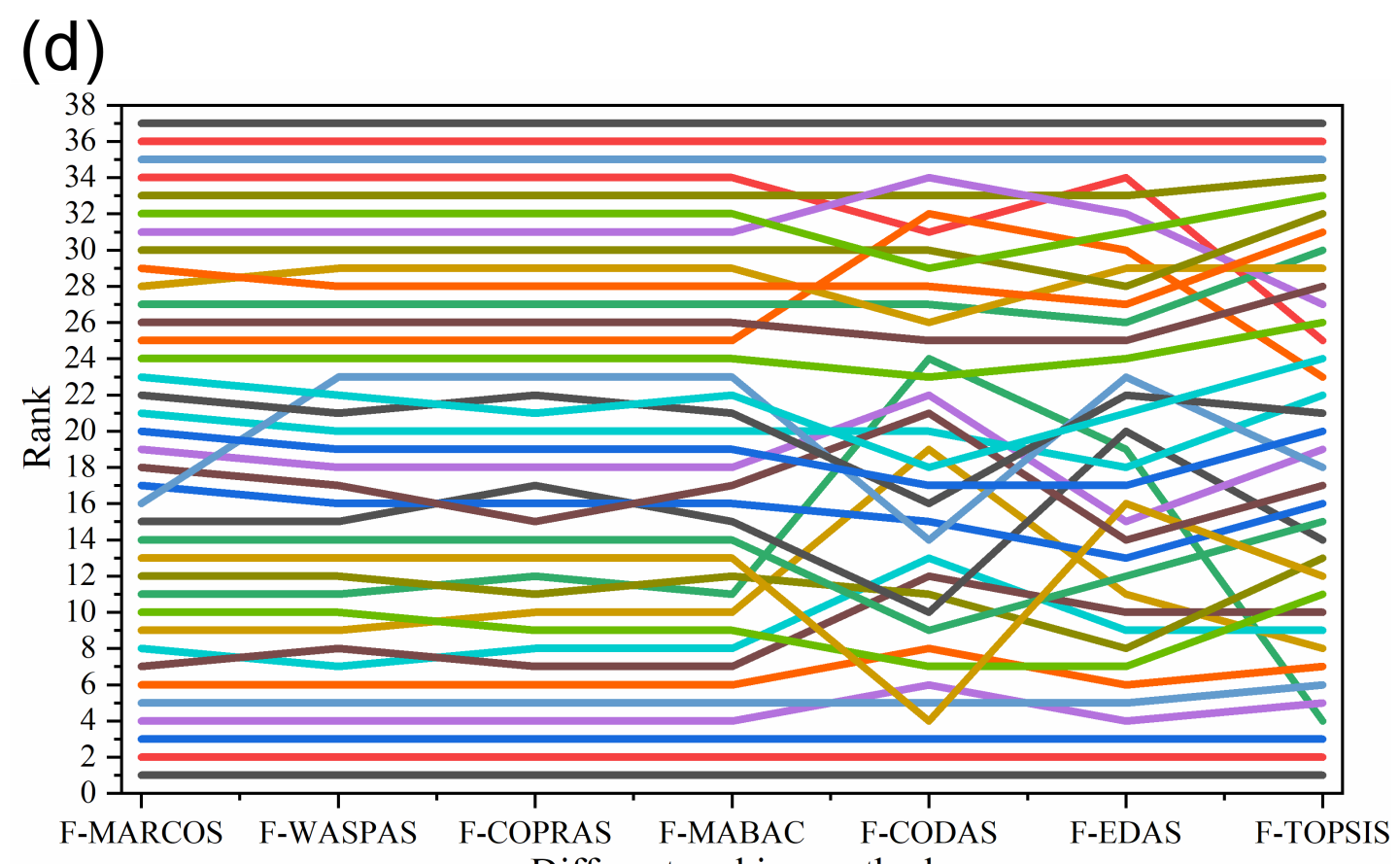

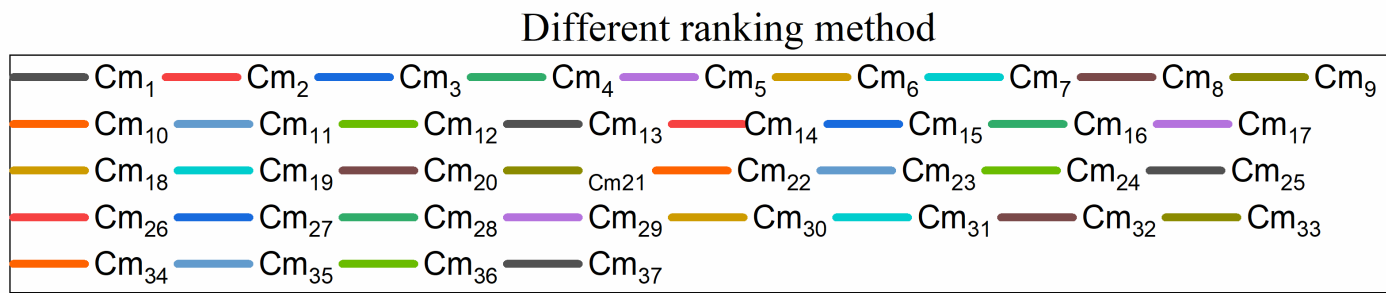

Fig. 6 Results of sensitivity analysis (a) effect of criteria weight change, (b) effect of dynamic matrices, (c) effect of different criteria weight calculation method, and (d) comparison with other MADM methods

\subsubsection{Coating material selection to enhance the heat transfer performance}

In the past study, this coating material selection problem was solved using three different MADM methods (VIKOR, TOPSIS, and COPRAS) (Mogra et al. 2021). Four different criteria were considered to evaluate the coating material selection, and for this study, it was taken from Table 2 of the past study (Mogra et al. 2021). Out of four criteria, two are beneficial (Thickness and thermal expansion coefficient), and two are non-beneficial criteria (Cost and contact angle). Weights of these criteria calculated using BWM methods and that are $w_{C l}=0.068, w_{C 2}=0.632$, $w_{C 3}=0.181$ and $w_{C 4}=0.12$. This problem was solved using the fuzzy-MARCOS method following by the procedure mentioned in section 3.2.2. 
Table 10 Final ranking of the alternatives

\begin{tabular}{|c|c|c|c|c|c|c|c|c|}
\hline Alternative & $f\left(K_{i}\right)$ & $\begin{array}{c}\text { F- } \\
\text { MARCOS }\end{array}$ & $\begin{array}{c}\text { AHP- } \\
\text { VIKOR } \\
\text { (Mogra et } \\
\text { al. 2021) }\end{array}$ & $\begin{array}{c}\text { E-VIKOR } \\
(\text { Mogra et } \\
\text { al. 2021) }\end{array}$ & $\begin{array}{c}\text { AHP- } \\
\text { COPRAS } \\
\text { (Mogra et } \\
\text { al. 2021) }\end{array}$ & $\begin{array}{c}\text { E- } \\
\text { COPRAS } \\
\text { (Mogra et } \\
\text { al. 2021) }\end{array}$ & $\begin{array}{c}\text { AHP- } \\
\text { TOPSIS } \\
\text { (Mogra et } \\
\text { al. 2021) }\end{array}$ & $\begin{array}{c}\text { E-TOPSIS } \\
\text { (Mogra et } \\
\text { al. 2021) }\end{array}$ \\
\hline $\mathrm{Cm}_{1}$ & 0.042 & 5 & 4 & 4 & 4 & 4 & 2 & 2 \\
\hline $\mathrm{Cm}_{2}$ & 0.051 & 4 & 5 & 2 & 5 & 5 & 1 & 3 \\
\hline $\mathrm{Cm}_{3}$ & 0.169 & 1 & 1 & 5 & 1 & 1 & 5 & 1 \\
\hline $\mathrm{Cm}_{4}$ & 0.096 & 3 & 3 & 1 & 2 & 3 & 4 & 4 \\
\hline $\mathrm{Cm}_{5}$ & 0.124 & 2 & 2 & 3 & 3 & 2 & 3 & 5 \\
\hline
\end{tabular}

From Table 10, it is observed that the ranking of the best alternative is similar to the ranking obtained in the past study (Mogra et al. 2021). There is a majority of MADM methods, which suggests $\mathrm{Cm}_{3}$ (CNT coating) is the best alternative. The Spearman's rank correlation coefficient between the ranking of alternatives was obtained in the acceptable range, i.e., $>0.8$. It reveals that ranking has an excellent correlation between them.

In addition to this, the obtained results were validated by performing the sensitivity analysis using four-phase methods (see sections 5.1, 5.2, 5.3, and 5.4). All four phases have the same opinion for the ranking of the best alternative $\left(\mathrm{Cm}_{3}-\mathrm{CNT}\right.$ coating). Figure 7 shows the effect of criteria wight change on the ranking of alternatives. The obtained ranking of alternatives has an excellent correlation as Spearman's rank correlation coefficient is more than 0.9. Similarly, the effect of dynamic matrices is presented in Fig. 7(b), where no changes are observed in the ranking of alternatives. The ranking of the best and worst alternatives is similar even though the criteria weight calculation method was changed (Fig. 7(c)), and the correlation coefficient between these rankings are in the acceptable range $(>0.7)$. A similar coefficient value $(>0.7)$ is obtained when the ranking was obtained using different fuzzy-MADAM methods. In this phase of sensitivity analysis, the ranking of the best alternative does not change, whereas ranking of the worst alternative changes in fuzzy-WASPAS and fuzzy-EDAS method (Fig. 7(d)). 
(a)

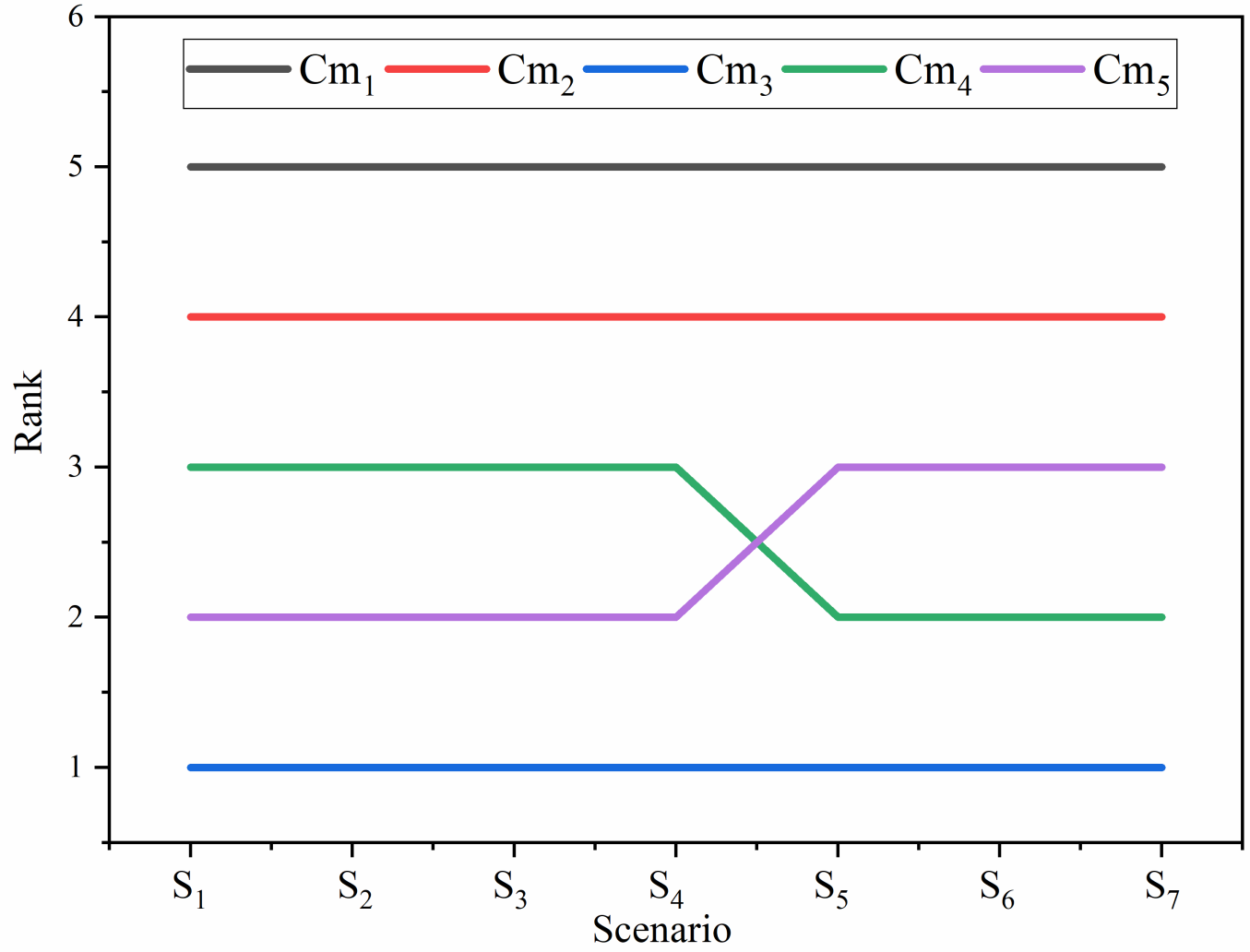

(b)

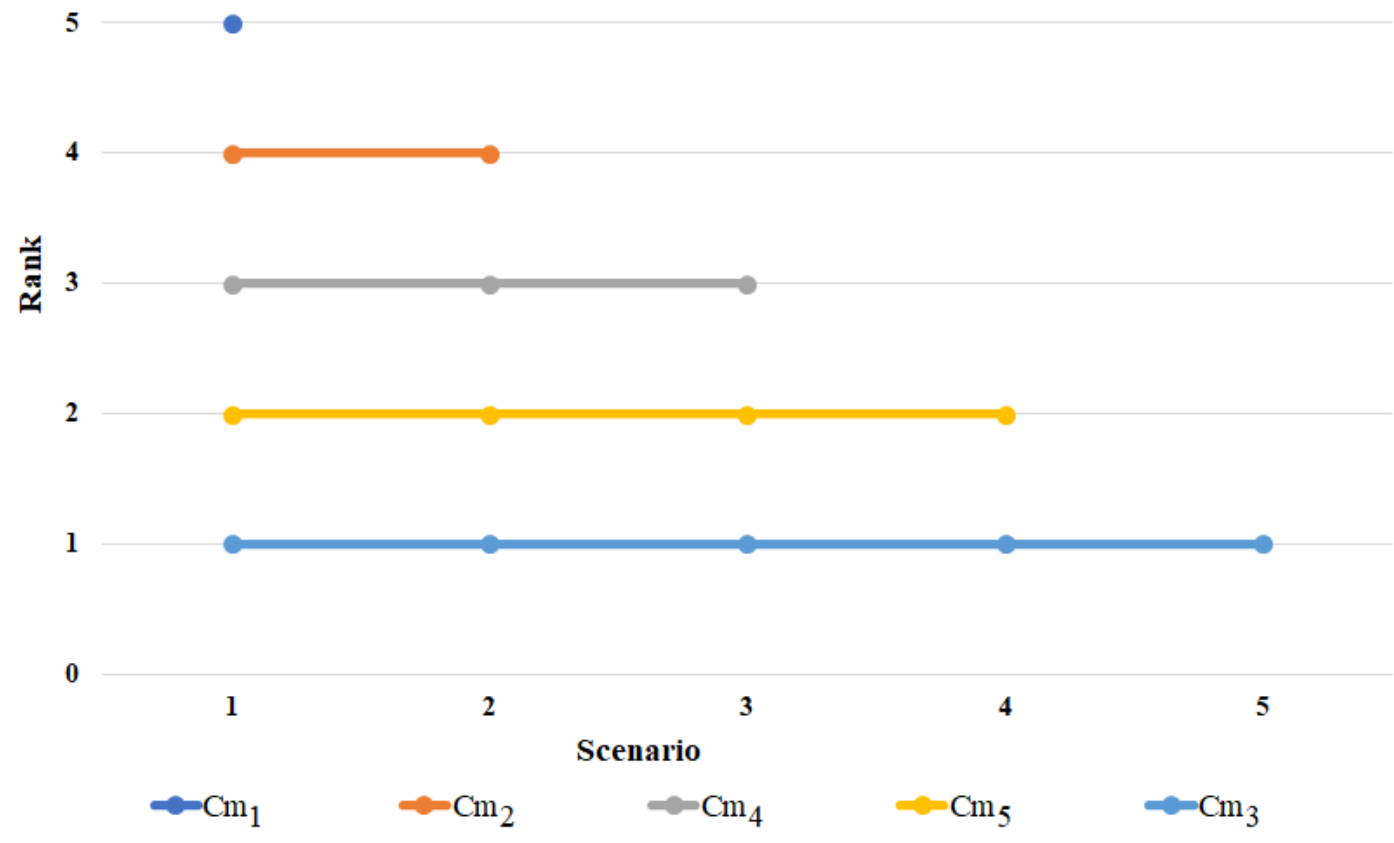


(c)

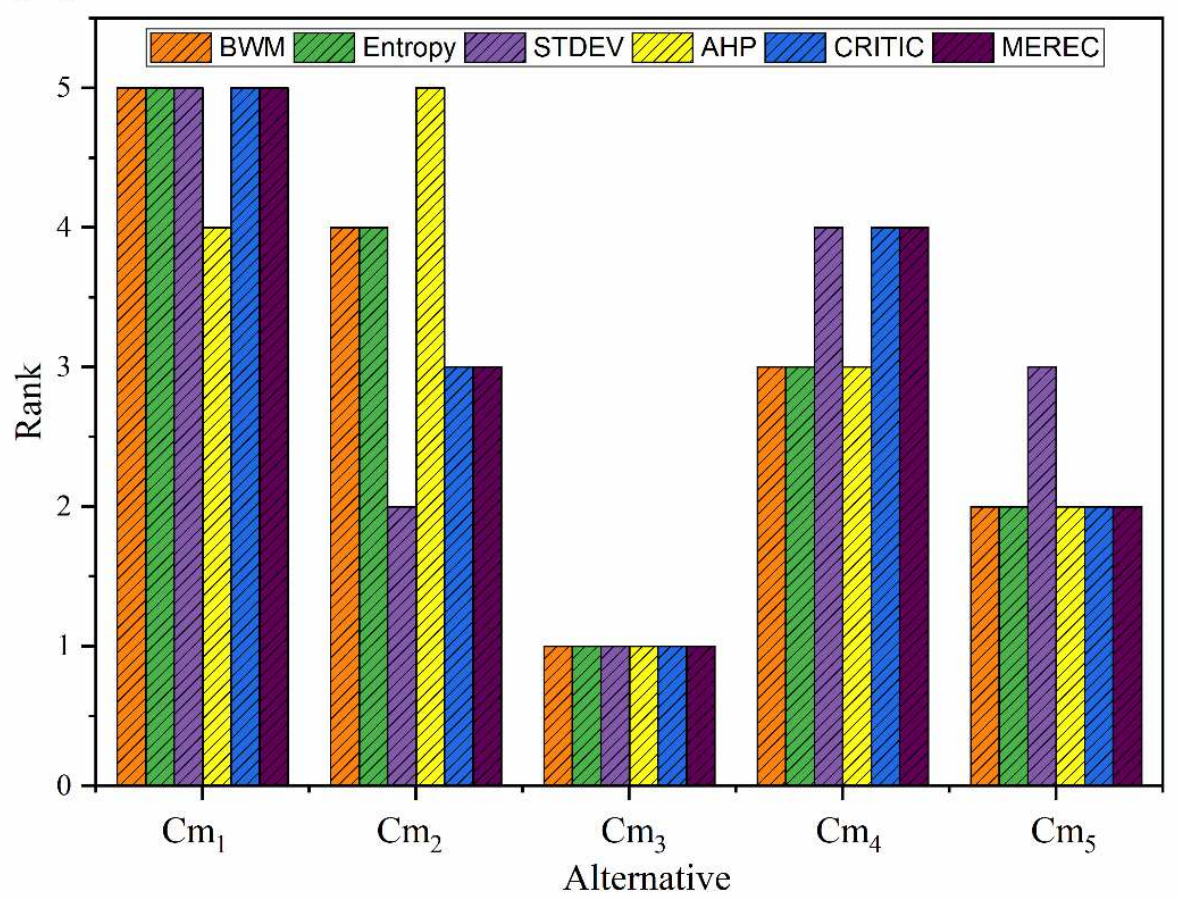

(d)

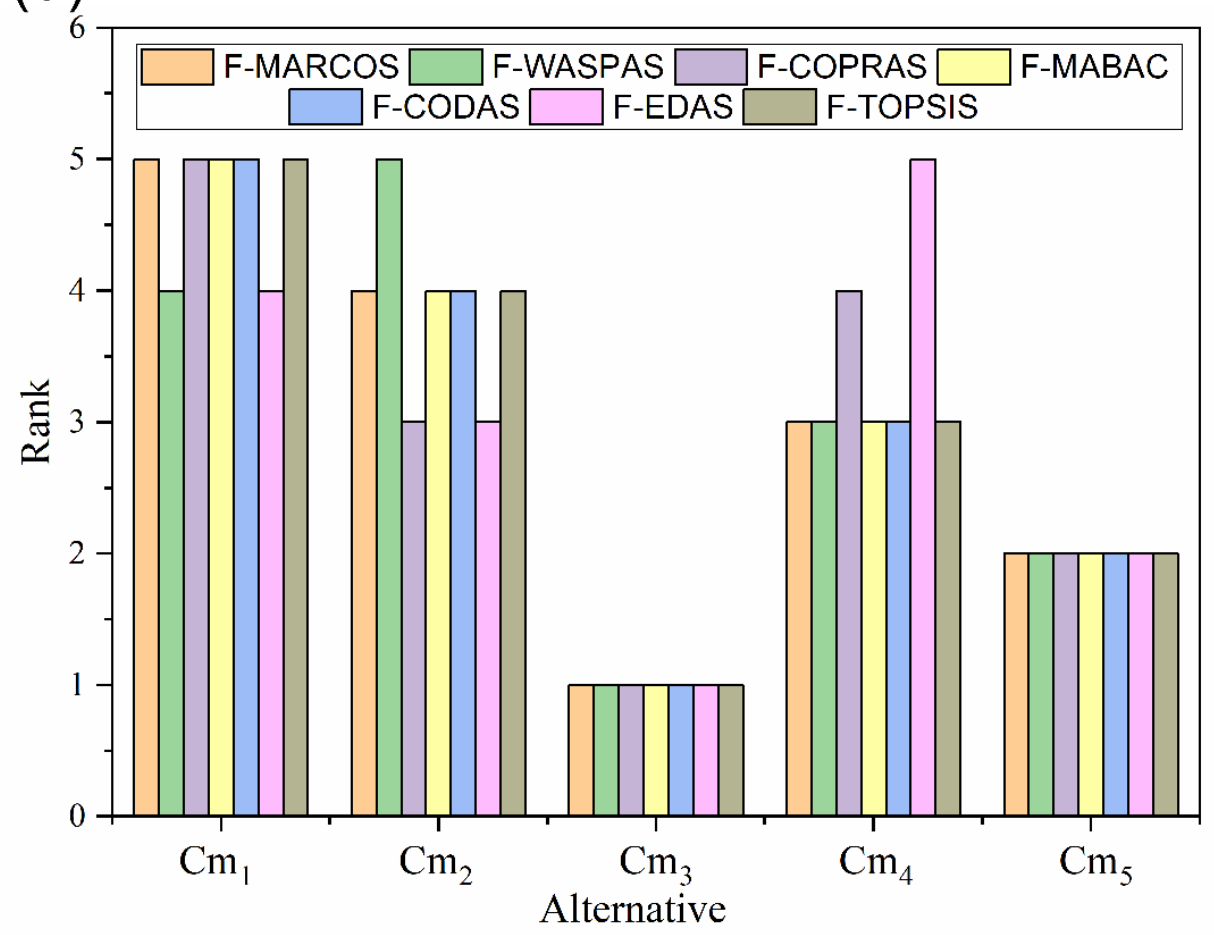

Fig. 7 Consequences of (a) criteria weight change and (b) dynamic matrices, ranking of alternative derived from different (c) criteria weight change method and (d) other MADM approaches 


\subsubsection{Coating material selection for magnesium alloy}

The present coating material selection problem was solved in the past research by Prasad et al. (2020) using the fuzzy-AHP integrated TOPSIS method. The coating alternative and its evaluation criteria are presented in Table 9 of this paper (Prasad et al. 2020). There are three beneficial (quantitative, qualitative, and quality) and three non-beneficial (coating structure, cost, and risk factor) criteria identified. The weights of these criteria derived using BWM method and those are $w_{C l}=0.041, w_{C 2}=0.088, w_{C 3}=0.146, w_{C 4}=0.362, w_{C 5}=0.146$ and $w_{C 6}=0.219$. This coating material selection problem was solved using the integrated BWM fuzzy-MARCOS method, and the results are presented in Table 11.

The obtained ranking by the fuzzy-MARCOS method remains similar to the ranking derived in the past study (Table 11). The present solution also suggesting $\mathrm{Cm}_{1}$ and $\mathrm{Cm}_{2}$ is the best and worst alternatives of coating material respectively for magnesium alloy. Both the rankings are strongly correlated with each other as Spearman's rank correlation coefficient is 0.82 . Hence the proposed method is an efficient and robust MADM tool to solve this type of problem.

Table 11 Final preference value and ranking of the coating alternative

\begin{tabular}{|c|c|c|c|}
\hline Alternative & $f\left(K_{i}\right)$ & F-MARCOS & TOPSIS (Prasad et al. 2020) \\
\hline $\mathrm{Cm}_{1}$ & 0.308 & 1 & 1 \\
\hline $\mathrm{Cm}_{2}$ & 0.227 & 7 & 7 \\
\hline $\mathrm{Cm}_{3}$ & 0.230 & 6 & 4 \\
\hline $\mathrm{Cm}_{4}$ & 0.245 & 4 & 3 \\
\hline $\mathrm{Cm}_{5}$ & 0.249 & 3 & 5 \\
\hline $\mathrm{Cm}_{6}$ & 0.237 & 5 & 6 \\
\hline $\mathrm{Cm}_{7}$ & 0.304 & 2 & 2 \\
\hline
\end{tabular}

Furthermore, to analyze the validity of obtained ranking, four phases of comparative sensitivity analysis were conducted. These phases are elaborated in sections 5.1, 5.2, 5.3, and 5.4. There are few changes observed in the ranking of alternatives corresponding to the different phases of sensitivity analysis (Fig. 8). But there are no such changes observed in the ranking of the best alternative, and it is similar for all the phases. Additionally, the correlation between ranking was 
derived using Spearman's rank correlation coefficient, and the overall coefficient value is 0.89 . It indicates rankings are excellently correlated to each other.

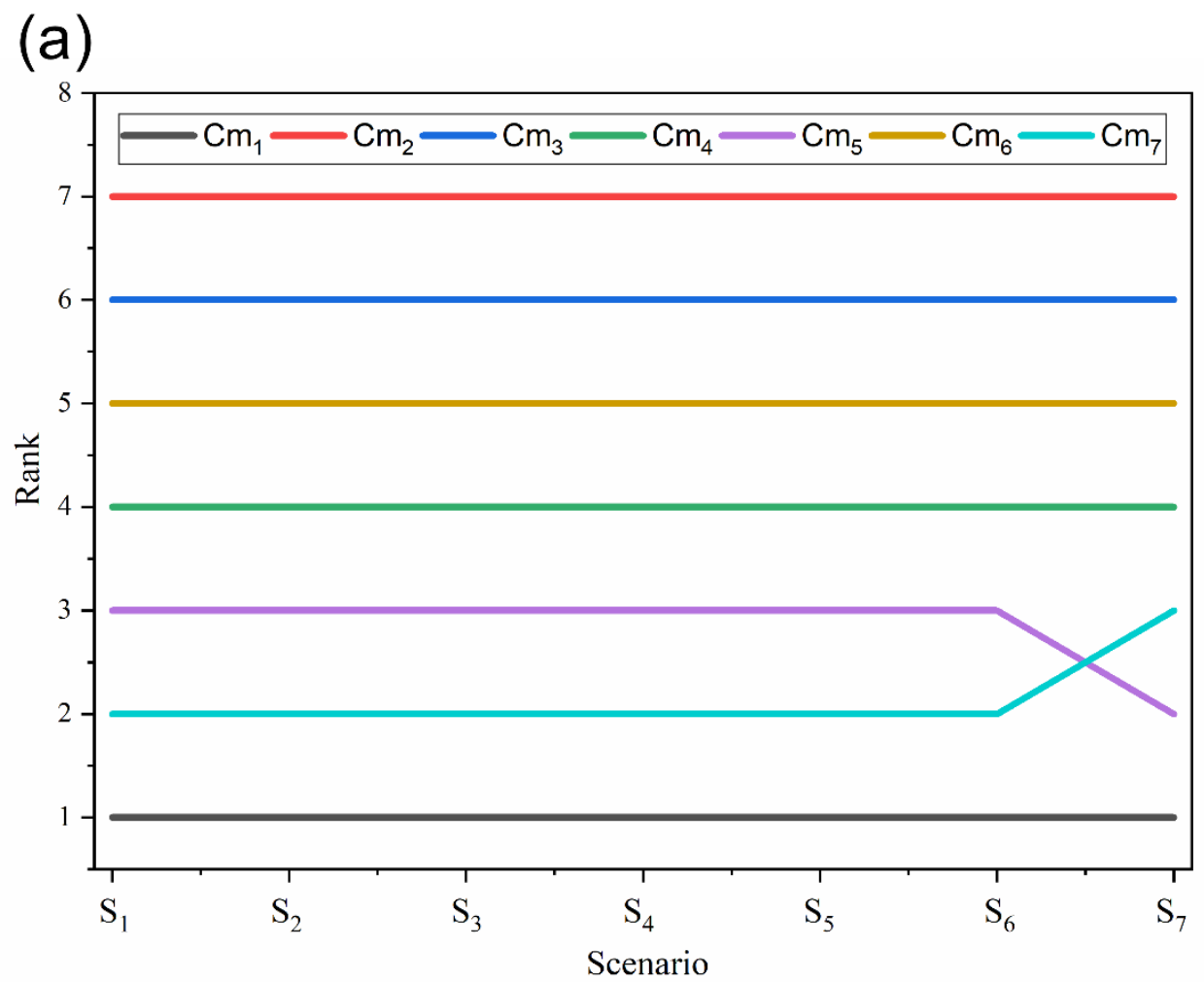

(b)

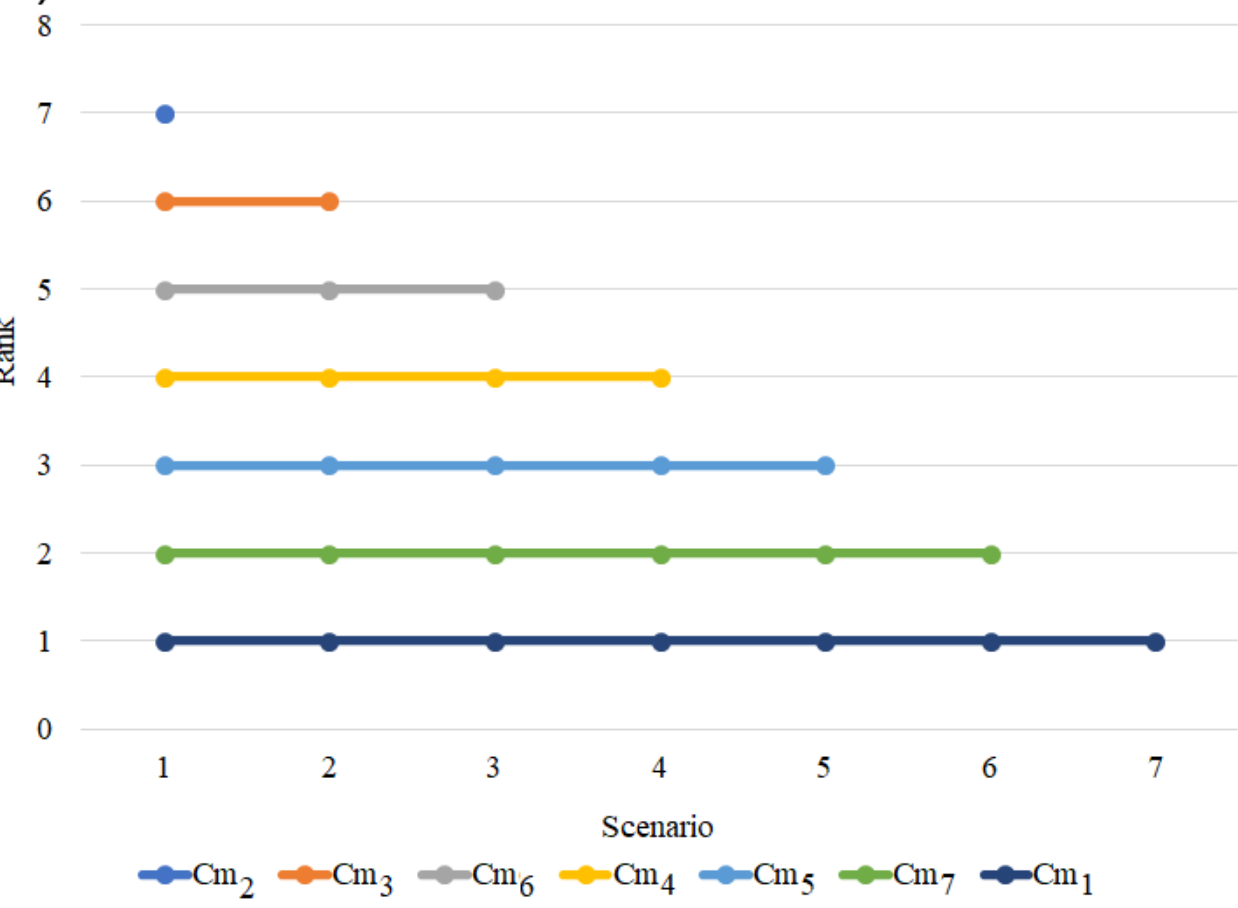



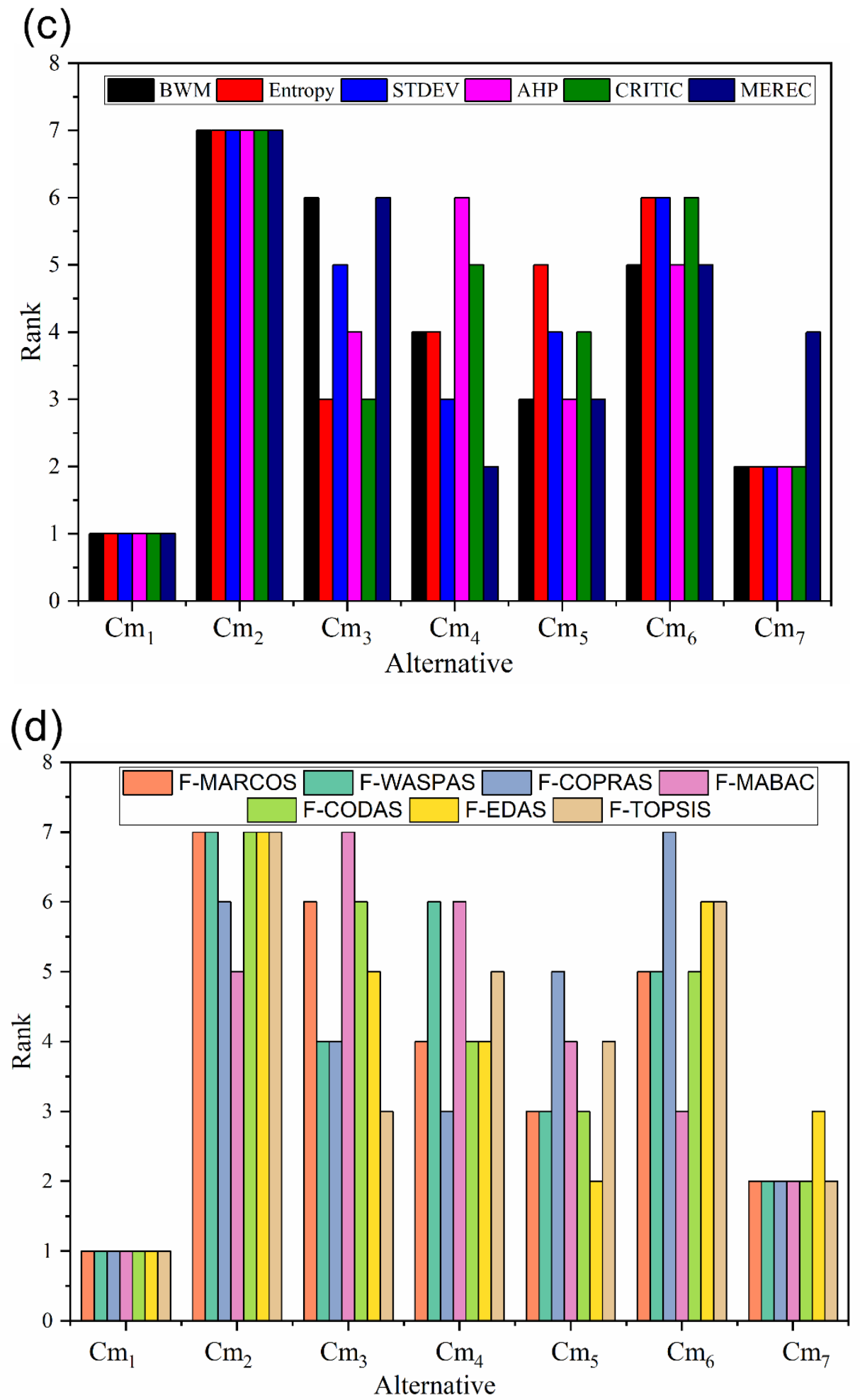

Fig. 8 Results of sensitivity analysis, effect of change in criteria weight (a) and dynamic matrices (b), effect of different methods used for criteria weight calculation (c), and ranking of alternative (d) 
From the above discussion, the ranking of the best alternative $\mathrm{Cm}_{5}(\mathrm{AlCrN} / \mathrm{TiAlN})$ in the present study does not change even though four phases of sensitivity analysis were used. Similarly, ranking of the best alternative for other coating material sections also has the same result. This indicates the reliability and robustness of the proposed integrated BWM fuzzy-MARCOS approach.

\section{Conclusions}

The objective of this study to fill the gap in aforementioned literature on material selection in tooling industries. It proposes a convenient integrated fuzzy-MADM method comprising BWM and the fuzzy-MARCOS approach to solve the coating material selection problem. The BWM and fuzzy-MARCOS approaches are novel MADM methods. However, it has been applied to solve the other multi-attributed decision-making problems experiences in the different fields. Literature does not exhibit a work applying this approach to solve the coating material selection problem for tooling industries in the literature. Although, detailed literature has been done in this work. The findings of this work proved that the proposed integrated model was effectively executed, and it gives valuable knowledge regarding the coating material section for the tooling industries.

The analytical findings have a critical suggestion to the tool designer who deals with tool design and its material section and the experts responsible for selecting coating material. Additionally, the proposed MADM method can be modified in future work integrated with some other models. New decision alternatives and criteria may transpire in future work with respect to the newly modified approach. It is also possible to use existing or new criteria and alternatives to extend the research work, as the proposed approach is ready to extend with modification.

\section{Declarations}

Funding No funding has been received for this work.

Conflicts of interest/Competing interests The authors declare there are no conflicts of interest.

Consent to Participate All the Authors are happily agreed to contribute in this research work.

Availability of data and material All the data has been incorporated in the manuscript.

Code availability Not applicable. 
Author's contributions SK, SRM and LP have designed and planned the work. SK and LP have conducted the experiments. SK, and SRM have contributed to data interpretation. SK wrote the first draft of the manuscript and all the authors contributed to editing the manuscript. All the authors were involved in the review and approval of the manuscript.

Ethics approval This work has not been published anywhere, and no animal and human subjects were used in this paper. The authors are agreed to keep the copy-right rule.

Consent for publication The authors are agreed to publish the manuscript in this reputed journal, and no individual person's data has been used.

\section{Acknowledgment}

The author would like to thank Indian Institute of Technology Kharagpur- Central Research facility (West Bengal, India), Centre for Nanoscience and Nanotechnology, Sathyabama University, Chennai (Tamil Nadu, India), Adhi college of Engineering Chennai, Ingenious Tools and Design Solution Ghaziabad for allocating essential infrastructure to perform the experiment.

\section{References}

Abreu LHP, Pimentel MCL, Borges WFA et al (2020) Plasma nitriding of AISI M2 steel: performance evaluation in forming tools. Surf Eng 36:508-515. $\underline{\text { https://doi.org/10.1080/02670844.2020.1727685 }}$

Adesina AY, Al-Badour FA, Gasem ZM (2018) Wear resistance performance of AlCrN and TiAlN coated H13 tools during friction stir welding of A2124/SiC composite. J Manuf Process 33:111125. https://doi.org/10.1016/j.jmapro.2018.04.019

Alao MA, Ayodele TR, Ogunjuyigbe ASO et al (2020) Multi-criteria decision based waste to energy technology selection using entropy-weighted TOPSIS technique: The case study of Lagos, Nigeria. Energy 201:117675. https://doi.org/10.1016/j.energy.2020.117675

Alkan Ö, Albayrak ÖK (2020) Ranking of renewable energy sources for regions in Turkey by fuzzy entropy based fuzzy COPRAS and fuzzy MULTIMOORA. Renew Energy 162:712-726. https://doi.org/10.1016/j.renene.2020.08.062 
Anitha J, Das R (2020) Optimization of EDM Process Parameters Using Standard Deviation and Multi-objective Optimization on the Basis of Simple Ratio Analysis (MOOSRA). In Intelligent Manufacturing and Energy Sustainability; Springer: Berlin/Heidelberg, Germany, pp 655-662.

Athanasopoulos G, Riba CR, Athanasopoulou C (2009) A decision support system for coating selection based on fuzzy logic and multi-criteria decision making. Expert Syst Appl 36:1084810853. https://doi.org/10.1016/j.eswa.2009.01.016

Beake BD, Endrino JL, Kimpton C et al (2017) Elevated temperature repetitive micro-scratch testing of AlCrN, TiAlN and AlTiN PVD coatings. Int J Refract Hard Mater 69:215-226. https://doi.org/10.1016/j.ijrmhm.2017.08.017

Chandrashekhar A, Kabadi VR, Bhide R (2016) Scratch wear resistance of TiALN and AlCrN coated EN-353 steel. J Mater Sci Eng 5(4):1-9. 10.4172/2169-0022.1000251

Chauhan A, Vaish R (2013) Hard coating material selection using multi-criteria decision making. Mater Des 44:40-245. https://doi.org/10.1016/j.matdes.2012.08.003

Das K, Alphonsa J, Ghosh M et al (2017) Influence of pretreatment on surface behavior of duplex plasma treated AISI H13 tool steel. Surf Interfaces 8:206-213. https://doi.org/10.1016/j.surfin.2017.06.009

Deirmina F, Peghini N, AlMangour B et al (2019) Heat treatment and properties of a hot work tool steel fabricated by additive manufacturing. Mater Sci Eng A 753:109-121. https://doi.org/10.1016/j.msea.2019.03.027

Díaz-Guillén JC, Alvarez-Vera M, Díaz-Guillén JA et al (2018) A hybrid plasma treatment of H13 tool steel by combining plasma nitriding and post-oxidation. J Mater Eng Perform 27(11):61186126. https://doi.org/10.1007/s11665-018-3669-z

Díaz-Guillén JC, Naeem M, Hdz-García HM et al (2020) Duplex plasma treatment of AISI D2 tool steel by combining plasma nitriding (with and without white layer) and post-oxidation. Surf Coat Technol 385:125420. https://doi.org/10.1016/j.surfcoat.2020.125420

Dumkum C, Jaritngam P, Tangwarodomnukun V (2019) Surface characteristics and machining performance of TiAlN-, TiN-and AlCrN-coated tungsten carbide drills. Proceed Inst Mech Eng Part B: J Eng Manuf 233:1075-1086. https://doi.org/10.1177/0954405418765307 
Ecer F, Pamucar D (2020) Sustainable supplier selection: A novel integrated fuzzy best worst method (F-BWM) and fuzzy CoCoSo with Bonferroni (CoCoSo'B) multi-criteria model. J Clean Prod 266:121981.

Fallahpour A, Nayeri S, Sheikhalishahi M (2021) A hyper-hybrid fuzzy decision-making framework for the sustainable-resilient supplier selection problem: A case study of Malaysian Palm oil industry. Environ Sci Pollut Res. https://doi.org/10.1007/s11356-021-12491-y

Fathallah BB, Dakhli CE, Terres MA (2019) The effect of grinding parameters and gas nitriding depth on the grindability and surface integrity of AISI D2 tool steel. Int J Adv Manuf Technol 104:1449-1459. https://doi.org/10.1007/s00170-019-03943-4

Firojkhan P, Kadam N, Dambhare SG (2020) Selection of Coating and Nitriding Process for AISI 4140 Steel Material to Enhance Tribological Properties. In Advanced Engineering Optimization Through Intelligent Techniques 463-473. Springer, Singapore. https://doi.org/10.1007/978-98113-8196-6 41

Gonzalez-Pociño A, Alvarez-Antolin F, Asensio-Lozano J (2019) Improvement of adhesive wear behavior by variable heat treatment of a tool steel for sheet metal forming. Materials 2(17):2831. https://doi.org/10.3390/ma12172831

Ho W (2008) Integrated analytic hierarchy process and its applications-A literature review. Eur J Oper Res 186:211-228. https://doi.org/10.1016/j.ejor.2007.01.004

Huber F, Bischof C, Hentschel O, et al (2019) Laser beam melting and heat-treatment of 1.2343 (AISI H11) tool steel-microstructure and mechanical properties. Mater Sci Eng A 42:109-115. https://doi.org/10.1016/j.msea.2018.11.001

Jokar K, Elmkhah H, Fattah-alhosseini A et al (2019) Comparison of the wear and corrosion behavior between $\mathrm{CrN}$ and AlCrN coatings deposited by Arc-PVD method. Mater Res Exp 6:116426. https://doi.org/10.1088/20531591/ab4645

Keshavarz-Ghorabaee M, Amiri M, Zavadskas EK et al (2021) Determination of Objective Weights Using a New Method Based on the Removal Effects of Criteria (MEREC). Symmetry 13:525. https://doi.org/10.3390/sym13040525 
Kheirandish S, Saghafian H, Hedjazi J et al (2010) Effect of heat treatment on microstructure of modified cast AISI D3 cold work tool steel. J Iron Steel Res Int 17:40-45. https://doi.org/10.1016/S1006-706X(10)60140-9

Kumar S, Maity SR, Patnaik L (2020a) Friction and tribological behavior of bare nitrided, TiAlN and AlCrN coated MDC-K hot work tool steel. Ceram Int 46:17280-17294. https://doi.org/10.1016/j.ceramint.2020.04.015

Kumar S, Maity SR, Patnaik L (2020b) Effect of heat treatment and TiN coating on AISI O1 cold work tool steel. Mater Today: Proceed 26:685-688. https://doi.org/10.1016/j.matpr.2019.12.367

Kumar S, Maity SR, Patnaik L (2021a) A comparative study on wear behaviors of hot work and cold work tool steel with same hardness under dry sliding tribological test. Mater Today: Proceed 44:949-954. https://doi.org/10.1016/j.matpr.2020.11.004

Kumar S, Maity SR, Patnaik L (2021b) Effect of tribological process parameters on the wear and frictional behaviour of $\mathrm{Cr}-(\mathrm{CrN} / \mathrm{TiN})$ composite coating: an experimental and analytical study. Ceram Int 47:16018-16028. https://doi.org/10.1016/j.ceramint.2021.02.176

Kumar S, Maity SR, Patnaik L (2021c) Effect of annealing on structural, mechanical and tribological properties of $\mathrm{Cr}-(\mathrm{CrN} / \mathrm{TiAlN})$ coating. Adv Mater Process Technol 1-14. https://doi.org/10.1080/2374068X.2021.1946755

Kumar S, Maity SR, Patnaik L (2021d) Relation between mechanical and tribological properties of plasma nitrided and TiCrN coated YXR-7 tool steel. In AIP Conference Proceed 2369:020033. AIP Publishing LLCAIP Publishing. https://doi.org/10.1063/5.0061159

Kundu P, Görçün ÖF, Kü̧̈ükönder H (2021) Medical device selection in private hospitals by integrated fuzzy MCGDM methods: A case study in choosing MRI (Magnetic Resonance Imaging) system. J Oper Res Soc 1-21. https://doi.org/10.1080/01605682.2021.1960910

Kara L, Asl HG, Karadayi Ö (2019) The effect of TiN, TiAlN, CrAlN, and TiAlN/TiSiN coatings on the wear properties of AISI H13 steel at room temperature. Surf Review Lett 26:1950063. https://doi.org/10.1142/S0218625X1950063X 
Lesyk DA, Martinez S, Mordyuk BN, et al (2017) Microstructure related enhancement in wear resistance of tool steel AISI D2 by applying laser heat treatment followed by ultrasonic impact treatment. Surf Coat Technol 328:344-354. https://doi.org/10.1016/j.surfcoat.2017.08.045

Liang W, Zhao G, Wu H et al (2019) Risk assessment of rockburst via an extended MABAC method under fuzzy environment. Tunn Undergr Space Technol 83:533-544. https://doi.org/10.1016/j.tust.2018.09.037

Maghsoodi AI, Mosavat M, Hafezalkotob A et al (2019) Hybrid hierarchical fuzzy group decisionmaking based on information axioms and BWM: Prototype design selection. Comput Ind Eng 127:788-804. https://doi.org/10.1016/j.cie.2018.11.018

Maity SR, Chakraborty S (2013) Grinding wheel abrasive material selection using fuzzy TOPSIS method. Mater Manuf Process 28:408-417. https://doi.org/10.1080/10426914.2012.700159

Maity SR, Chakraborty S (2015) Tool steel material selection using PROMETHEE II method. Int J Adv Manuf Technol 78:1537-1547. https://doi.org/10.1007/s00170-014-6760-0

Miyamoto J, Abraha P (2019) The effect of plasma nitriding treatment time on the tribological properties of the AISI H13 tool steel. Surf Coat Technol 375:15-21. https://doi.org/10.1016/j.surfcoat.2019.07.001

Mogra A, Pandey PK, Gupta KK (2021) Influence of surface wettability and selection of coating material for enhancement of heat transfer performance. Mater Today: Proceed 44:4433-4438. https://doi.org/10.1016/j.matpr.2020.10.595

Mousavi-Nasab SH, Sotoudeh-Anvari A (2017) A comprehensive MCDM-based approach using TOPSIS, COPRAS and DEA as an auxiliary tool for material selection problems. Mater Des 121:237-253. https://doi.org/10.1016/j.matdes.2017.02.041

Niu J, Huang C, Li C et al (2020) A comprehensive method for selecting cutting tool materials. Int J Adv Manuf Technol 110:229-240. https://doi.org/10.1007/s00170-020-05534-0

Özkan D, Erarslan Y, Sulukan E (2018) Tribological behavior of TiAlN, AlTiN, and AlCrN coatings at boundary lubricating condition. Tribolo Letters 66:1-16. https://doi.org/10.1007/s11249-018-1111-1 
Pahan F, Dambhare S, Mali A et al (2018) Implementation of multi-criteria decision making for selection of coating material on AISI 4140 steel. Int Res J Eng Technol 5:1514-1517.

Patel RD, Bhavsar SN (2020) Experimental investigation during end milling of AISI D2 tool steel using AlCrN coated tool. Mater Today: Proceed 22:2647-2656. https://doi.org/10.1016/j.matpr.2020.03.396

Peng X, Krishankumar R, Ravichandran KS (2021) A novel interval-valued fuzzy soft decisionmaking method based on CoCoSo and CRITIC for intelligent healthcare management evaluation. Soft Comput 25:4213-4241. https://doi.org/10.1007/s00500-020-05437-y

Petković D, Madić M, Radovanović M et al (2015) Application of Recently Developed MCDM Methods for Materials Selection. Appl Mech Mater 809:1468-1473. https://doi.org/10.4028/www.scientific.net/AMM.809-810.1468

Podgornik B, Hogmark S, Sandberg O (2006) Proper coating selection for improved galling performance of forming tool steel. Wear 261:15-21. http://dx.doi.org/10.1016/j.wear.2005.09.005 Podgornik B, Majdic F, Leskovsek V et al (2012) Improving tribological properties of tool steels through combination of deep-cryogenic treatment and plasma nitriding. Wear 288:88-93. https://doi.org/10.1016/j.wear.2011.04.001

Polat G, Bayhan HG (2020) Selection of HVAC-AHU system supplier with environmental considerations using Fuzzy EDAS method. Int J Constr Manag 1-9. https://doi.org/10.1080/15623599.2020.1742638

Puška LA, Kozarević S, Stević Ž (2018) A new way of applying interval fuzzy logic in group decision making for supplier selection. Econ Comput Econ Cybern Stud Res 52. DOI: $\underline{10.24818 / 18423264 / 52.2 .18 .13}$

Prasad RV, Rajesh R, Thirumalaikumarasamy D (2020) Selection of coating material for magnesium alloy using Fuzzy AHP-TOPSIS. Sādhanā 45:1-20. https://doi.org/10.1007/s12046019-1261-3

Rezaei J (2015) Best-worst multi-criteria decision-making method. Omega 53:49-57. https://doi.org/10.1016/j.omega.2014.11.009 
Robinson P, Matthews A, Swift KG et al (1993) A computer knowledge-based system for surface coating and material selection. Surf Coat Technol 62:662-668.

Saber-Samandari S, Berndt CC, Gross KA (2011) Selection of the implant and coating materials for optimized performance by means of nanoindentation. Acta Biomater 7:874-881. https://doi.org/10.1016/j.actbio.2010.09.023

Sahoo P, Patra K, Singh VK et al (2020) Influences of TiAlN coating and limiting angles of flutes on prediction of cutting forces and dynamic stability in micro milling of die steel (P-20). J Mater Process Technol 278:116500. https://doi.org/10.1016/j.jmatprotec.2019.116500

Salih MM, Zaidan BB, Zaidan AA (2019) Survey on fuzzy TOPSIS state-of-the-art between 2007 and 2017. Comput Oper Res 104:207-227. https://doi.org/10.1016/j.cor.2018.12.019

Souza PS, Santos AJ, Cotrim MA et al (2020) Analysis of the surface energy interactions in the tribological behavior of ALCrN and TIAlN coatings. Tribol Int 146:106206. https://doi.org/10.1016/j.triboint.2020.106206

Sousa VF, Silva FJG, Alexandre R (2021) Study of the wear behaviour of TiAlSiN and TiAlN PVD coated tools on milling operations of pre-hardened tool steel. Wear 203695. https://doi.org/10.1016/j.wear.2021.203695

Staia MH, Pérez-Delgado Y, Sanchez C et al (2009) Hardness properties and high-temperature wear behavior of nitrided AISI D2 tool steel, prior and after PAPVD coating. Wear 267:14521461. https://doi.org/10.1016/j.wear.2009.03.045

Stević Ž, Pamučar D, Puška A (2020) Sustainable supplier selection in healthcare industries using a new MCDM method: Measurement of alternatives and ranking according to COmpromise solution (MARCOS). Comp Ind Eng 140:106231. https://doi.org/10.1016/j.cie.2019.106231

Turskis Z, Zavadskas EK, Antucheviciene J (2015) A hybrid model based on fuzzy AHP and fuzzy WASPAS for construction site selection. Int J Comput commun control 10:113-128.

Ulutas A, Topal A, Bakhat R (2019) An application of fuzzy integrated model in green supplier selection. Math Probl Eng 1-11. https://doi.org/10.1155/2019/4256359 
Yadav G, Mangla SK, Luthra S et al (2018a) Hybrid BWM-ELECTRE-based decision framework for effective offshore outsourcing adoption: a case study. Int J Product Res 56:6259-6278. https://doi.org/10.1080/00207543.2018.1472406

Yadav G, Seth D, Desai TN (2018b) Application of hybrid framework to facilitate lean six sigma implementation: a manufacturing company case experience. Prod Plan Control 29:185-201. https://doi.org/10.1080/09537287.2017.1402134

Yalçın N, Yapıcı Pehlivan N (2019) Application of the fuzzy CODAS method based on fuzzy envelopes for hesitant fuzzy linguistic term sets: A case study on a personnel selection problem. Symmetry11:493. https://doi.org/10.3390/sym11040493 


\section{Supplementary Files}

This is a list of supplementary files associated with this preprint. Click to download.

- Supportingdata1.docx 